\title{
Current electroconvulsive therapy practice and research in the geriatric population
}

\author{
Nancy Kerner ${ }^{*}, 1$ and Joan Prudic ${ }^{1}$ \\ ${ }^{1}$ Electroconvulsive Therapy Service \& the Division of Geriatric Psychiatry, New York State \\ Psychiatric Institute, \& the College of Physicians \& Surgeons of Columbia University, 1051 \\ Riverside Drive, New York, NY 10032, USA
}

\section{SUMMARY}

Electroconvulsive therapy (ECT) is utilized worldwide for various severe and treatment-resistant psychiatric disorders. Research studies have shown that ECT is the most effective and rapid treatment available for elderly patients with depression, bipolar disorder and psychosis. For patients who suffer from intractable catatonia and neuroleptic malignant syndrome, ECT can be life saving. For elderly patients who cannot tolerate or respond poorly to medications and who are at a high risk for drug-induced toxicity or toxic drug interactions, ECT is the safest treatment option. Organic causes are frequently associated with late-life onset of neuropsychiatric conditions, such as parkinsonism, dementia and stroke. ECT has proven to be efficacious even when these conditions are present. During the next decade, research studies should focus on the use of ECT as a synergistic therapy, to enhance other biological and psychological treatments, and prevent symptom relapse and recurrence.

Electroconvulsive therapy (ECT) is a biological treatment procedure involving a brief application of electric stimulus to produce a generalized seizure. ECT is utilized worldwide as one of the most effective biological treatment modalities for various severe, treatmentrefractory or treatment-resistant psychiatric disorders, in particular, major depressive disorder (MDD) in western countries and schizophrenia in Asian countries [1]. In the USA, approximately 100,000 patients receive ECT annually [2]. Outpatient ECT, as a continuation treatment or an independent acute course, has become a trend over the past 20 years [2-4]. Data from the National Institute of Mental Health survey sample showed that a third of ECT recipients were aged 65 years and older; of patients with affective disorders, $3.4 \%$ of those under the age of 65 years received ECT, while $15.6 \%$ of those 65 years of age and older received ECT [5].

Several factors may be relevant to a higher rate of ECT utilization in the geriatric population. First, medication has not been more effective than placebo for treatment of late-

\footnotetext{
(C) 2014 Future Medicine Ltd

*Author for correspondence: nak2120@ columbia.edu.

Financial \& competing interests disclosure

The authors have no other relevant affiliations or financial involvement with any organization or entity with a financial interest in or financial conflict with the subject matter or materials discussed in the manuscript apart from those disclosed.

No writing assistance was utilized in the production of this manuscript.
} 
life depression in several studies [6-9], particularly in depressed patients with cerebral small-vessel disease [10-13]. Second, elderly patients have a lower tolerance to medication owing to age-associated pharmacokinetic changes and increased sensitivity to psychotropic medications, such as anticholinergic and orthostatic hypotensive side effects. In comparison with pharmacotherapy, ECT may pose less risk of complications in elderly patients [14]. Third, depressed elderly patients often have a better treatment response to ECT than young adults $[15,16]$. Fourth, elderly patients have higher rates of neuropsychiatric comorbidities than younger adults. ECT can be effective in treating neuropsychiatric conditions, such as catatonia and parkinsonism.

\section{History of ECT}

Convulsive therapy was reintroduced in 1934 by the neuropsychiatrist Meduna, who, based on his theory of "a biological antagonism between epilepsy and schizophrenia", chemically induced a therapeutic generalized seizure in a catatonic schizophrenia patient [17]. In 1938, a neurologist, Ugo Cerletti, used electricity as an alternative method of inducing a therapeutic seizure, in the treatment of a delusional and incoherent patient, and elicited dramatic clinical improvement. With the introduction of ECT, mortality rates in elderly mentally ill patients were markedly reduced. A retrospective study analyzed all cases with depression $(n=935)$ in a UK psychiatric hospital $[18,19]$. The study compared the mortality rates between treatment as usual and ECT in patients aged 56 years and older. Between 1930 and 1939 when ECT was not available for treatment, the mortality rate was 31\% (46 out of 149 patients); between 1940 and 1948, the mortality rate was $26.5 \%$ (31 out of 117 patients) with treatment as usual, while it was 3\% (one out of 35 patients) with ECT treatment. The result is striking, indicating that ECT may have a positive impact on older mentally ill patients. In addition, $86 \%$ of patients recovered or improved with ECT, and $60 \%$ of patients with treatment as usual in this age group, respectively.

In the 1940s and 1950s, ECT was the mainstay of biological treatment in psychiatry. It was often administrated to the most severely disturbed patients residing in large mental institutions [20]. Unmodified ECT (i.e., treatment without anesthesia) was frequently given in a higher dose for a longer period than modified ECT that is given today [20]. Harmful events, such as fractures, dislocations and dental injury, were adverse effects associated with unmodified ECT [21]. In the 1950s, efforts to improve the safety profile of ECT were undertaken, including brief general anesthesia with barbiturates and succinylcholine, oxygen supplementation and cardiopulmonary monitoring. Nonetheless, ECT was claimed to be at least as effective and well tolerated as pharmacotherapy for unipolar and bipolar depression in the geriatric population [22]. In the late 1970s, efforts to protect patients by standardizing consent and the technical and clinical aspects of the conduct of ECT were undertaken in the USA [23]; the APA Task Force was established and has recommended practice, training and privileges standards [24].

In 1985, the National Institute of Mental Health Consensus Panel advocated research and practice standards for ECT [25]. Following that, efforts to assure uniformly high standards of ECT practice were promoted with the publication of guidelines by professional organizations in the USA, England, Scandinavia and Canada, among others [26]. In the 
1980s and 1990s, evidence from both research studies and clinical practice suggested that ECT had greater short-term efficacy than antidepressants in major depression and bipolar depression [27-29], at least equal efficacy to lithium in acute mania [30-32], and comparable efficacy with antipsychotics in schizophrenia/schizoaffective disorder [33-35]. Research studies also demonstrated that combined treatment with antipsychotic drug and ECT was characterized by a faster reduction of symptom severity and lower relapse rates compared with antipsychotic drug alone [34,36-42].

In 1990, the APA Task Force suggested ECT treatment over pharmacotherapy under certain circumstances including: the need for rapid or definitive response; the risks of other treatments outweighting the risks of ECT; prior treatment failure; and patient preference. In addition, the APA Task Force also recommended that treating psychiatrists consider unilateral ECT over bilateral (BL) ECT because unilateral electrode placement, while providing equivalent efficacy when dosed properly, is generally associated with fewer memory and cognitive side effects than BL electrode placement [14]. In the late 1990s, the benefits of right unilateral (RUL) ECT were validated in control trials: RUL electrode placement was associated with significantly fewer adverse cognitive side effects than BL electrode placement [43]; high-dosage RUL ECT $(6.0 \times$ seizure threshold [ST]) was as effective as high-dosage BL ECT $(2.5 \times \mathrm{ST})[43,44]$.

In the 2000s and 2010s, sophisticated clinical research on ECT continued to grow. In 2001, results from a multicenter, randomized, double-blind, placebo-controlled trial showed that nortriptyline-lithium combination therapy had a marked advantage in time to relapse, superior to both placebo and nortriptyline alone. Over the 24-week trial, the relapse rates for nortriptyline-lithium, placebo and nortriptyline were 39, 60 and 84\%, respectively [45]. Venlafaxine combined with lithium from a recent randomized, placebo-controlled study was shown to be equivalent to nortriptyline-lithium combination therapy in maintaining remission post-ECT [46]. In contrast to nortriptyline, venlafaxine is well tolerated and has a better safety profile for elderly patients. Continuation ECT (C-ECT), shown to be at least equivalent to continuation pharmacotherapy, is an excellent alternative for elderly patients who cannot tolerate medications or who relapse on adequate post-ECT pharmacotherapy after a successful course of ECT.

\section{Evidence base for ECT effectiveness, efficacy \& tolerability in older adults Major depressive disorder}

The three leading causes of disease burden in 2030 are projected to be HIV/AIDS, unipolar depressive disorders and ischemic heart disease. Unipolar depression was ranked the fourth cause of disease burden in 2002; and it is projected to be the second worldwide and the first in high-income countries (e.g., USA) in 2030 [47]. Depression is highly comorbid with the other two leading causes, HIV/AIDS and ischemic heart disease [48,49]. The prevalence of major depression was $5.5 \%$ in individuals over 65 years of age [50]. The highest prevalence of major depression was in nursing homes and other residential settings [51]. Untreated and undertreated elderly with major depression have higher rates of mortality and morbidity $[52,53]$. Although it is a treatable illness, major depression can be chronic and recurrent. 
The efficacy of ECT in major depression is well established. Data from comparative trials showed that the antidepressant effects of ECT are greater than any pharmacologic agent, including monoamine oxidase inhibitors [54], tricyclics [29,55,56], and serotonin reuptake inhibitors [28]. A large, multisite collaborative study showed that, among 217 patients, 86\% completed an acute treatment course with three-times a week BL ECT, 79\% showed sustained improvement and 75\% remitted [57]. This study suggests that ECT has a rapid effect and high remission rates compared with $25-35 \%$ remission rates with pharmacotherapy [58]. For pharmacotherapy treatment-resistant major depression, 50\% or more can respond to ECT $[59,60]$.

A large body of literature indicates that ECT is an effective and safe treatment option for elderly patients with major depression, even in very old-old age ( $>85$ years). Efficacy of ECT is markedly greater in older patients as compared with younger patients [16,61-63]. Yet, an observational study found that the time course of response to ECT can be variable, possibly longer for elderly patients. Hence, the study suggests that ECT should not be abandoned when rapid response is not seen [64]. From a long-term care prospective, results from a survival analysis of a large follow-up study showed that older adults with major depression, who received ECT, lived longer and had a greater clinical improvement compared with patients who received treatment with pharmacotherapy only [65].

\section{Subtypes of major depression}

Melancholic depression is a severe form of major depression with the loss of capacity to derive pleasure from positive stimuli and a high rate of hospitalization. It is commonly seen in late-onset major depression ( $\ 60$ years) [66]. Owing to its distinct clinical features, researchers had investigated whether melancholic depression responds to ECT differently from other affective disorders. Early case reports and series suggested that melancholic features could predict a positive outcome with ECT, but more recent studies found that melancholic features were less reliable predictors. Data from a the Consortium for Research on Electroconvulsive Therapy (CORE) study involving 311 patients with MDD found that ECT remission rates were $62.1 \%$ with melancholic MDD and $78.7 \%$ non-melancholic MDD. During a 6-month follow-up, patients with melancholic features were less likely to relapse with C-ECT than with continuation pharmacotherapy (nortriptyline plus lithium) [67]. For patients who have a partial response to ECT, melancholic features have little predictive value [68]. For ECT-naive patients, although increasing stimulus intensity might yield a more rapid onset of response, ECT does not affect the degree of melancholic symptom improvement or number of ECT required to achieve a therapeutic response in a large randomized trial [69].

Delusions have a higher prevalence in late-onset major depression (>60 years of age) [70]. A retrospective review concluded that depressed patient with psychotic delusion can be five times more likely to commit suicide than a nondelusional one [71]. Overall, delusional depression has a poorer prognosis than nonpsychotic depression [72], and is less responsive to antidepressants [73]. ECT was significantly more effective than sham ECT in delusional depression as documented in three double-blind, placebo-controlled trials (Leicester, Northwick Park and Nottingham). However, studies found the differences of ECT response 
rates between delusional and nondelusional depression were not large [74], but remission rates were greater and symptoms improved earlier with ECT in delusional depression [75]. Currently, patients referred for ECT are those who need rapid treatment response in the setting of failed multiple antidepressant trials, as well as combined treatment with antidepressants and antipsychotic drugs. For elderly patients with severe depression and psychotic features, ECT may be the most effective and rapid treatment available $[14,76]$.

\section{Bipolar disorder}

A community-based epidemiological study reported the prevalence of bipolar disorder in adults over 65 years was $0.08 \%$ [77]. However, a survey of nursing home elderly residents reported the prevalence of bipolar disorder was 10\% [78], and the Veterans Affairs Hospitals in federal fiscal year 2001 showed that $24.9 \%$ of bipolar patients were over 60 years of age [79]. Late-life onset of bipolar disorder is highly associated with neuropsychiatric conditions [80]. Hence, older adults who present with new-onset mania should have a complete medical evaluation and a neuropsychiatric work-up before ECT.

Pharmacotherapy is the first-line treatment for bipolar disorder and lithium is the oldest effective mood stabilizer for bipolar disorder. However, elderly patients have poorer tolerance of lithium compared with younger patients. First, age-related pharmacokinetic changes, including absorption, distribution, plasma protein-binding, hepatic metabolism and renal clearance, predispose older patients to a higher risk of lithium toxicity [81]. Second, lithium neurotoxicity (e.g., sedation, confusion, delirium and memory impairment) can occur even within therapeutic range in older individuals owing to age-dependent changes in tissue sensitivity to the action of the drug (pharmacodynamics) [82]. Third, serum lithium levels can significantly increase due to drug-drug interactions between lithium and medications frequently prescribed for elderly, such as thiazide diuretics and ACE inhibitors for hypertension, and NSAIDs for arthritis [83]. However, other medication options for bipolar disorder also have unfavorable side effects and significant drug-drug interactions, for example, carbamazepine is a potent CYP450 inducer and valproic acid is a potent CYP450 inhibitor.

ECT is highly effective for bipolar depression, with no reported difference in degree of improvement in bipolar depression compared with unipolar depression [84]. Daly and colleagues [87]contrasted a sample $(n=228)$ from three double-blind trials $[43,85,86]$ conducted in an academic medical center, and found that ECT for bipolar depression was as effective as for unipolar depression regardless of anatomical positioning of the electrode placement. Moreover, there were significantly more rapid clinical improvement and shorter treatment course in bipolar depression than in unipolar depression [87]. A recent study of hospitalized patients treated with ECT reported that the number of treatments needed to achieve remission in patients with bipolar depression (mean \pm standard deviation: $7.5 \pm 1.6$ ) was lower than in patients with unipolar depression (mean \pm standard deviation: 10.2 \pm 1.9 ) [88]. Several studies suggested that fewer ECT treatments were required to achieve comparable benefits in bipolar disorder than unipolar depression [84,87-89]. Therefore, ECT can be an excellent alternative treatment option for elderly patients with bipolar disorder who cannot tolerate pharmacotherapy. 
ECT has been used to treat mania since the 1940s. The paucity of rigorous clinical trials to support the antimanic effects of ECT is a major factor limiting the use of ECT for mania. In addition, early case reports and series might have discouraged the use of ECT for mania because extended courses of ECT and/or frequent treatment (i.e., daily ECT) were recommended to achieve symptom improvement or remission [90]. More recent studies have shown that remission rates for mania are greater than for bipolar depression after an acute course of ECT [91]. A second factor limiting the use of ECT for the treatment of mania is the substantial efficacy of mood stabilizers for mania, including antiepileptic drugs, lithium and antipsychotics/atypical antipsychotics. One early-controlled study, conducted before pharmacotherapy was standard for mania, assessed the efficacy of ECT compared with conservative treatment (control group). Both the ECT group and the control group consisted of 17 women and 11 men with a mean age of 33 years. Results from the study showed that ECT had a favorable treatment outcome compared with conservative treatment: the average length of hospital stay was $6.5 \pm 2.13$ days in the ECT group and $15.3 \pm 11.3$ days in the control group, and the overall symptom improvement was $96 \%$ in the ECT group and $44 \%$ in the control group [92]. The advantage of this study is that patients in both the ECT group and the control group were drug naive, which made the comparison more compelling. Nevertheless, this study was a retrospective study and the design was not randomized or double blind. Later studies found that the effectiveness of ECT was superior to lithium during the acute treatment phase, but the superiority did not extend behind 8 weeks [30,93]. However, patients who received ECT had longer remissions [93] and a lower risk of rehospitalization [94]. By contrast, Medda's study found that patients with bipolar I tended to exhibit residual manic and psychotic symptomatology after an acute ECT course with BL ECT [95].

It is controversial whether the difference in anatomical positioning of electrode placement has a significant impact on the efficacy of ECT in bipolar mania. Some have suggested that unilateral ECT had no effect on mania while strongly supporting the effects of BL ECT $[96,97]$. For instance, one case series reported that six manic patients did not improve with unilateral ECT but showed clinical improvement after switching to BL ECT [98]. However, such results could be confounded by a requirement for a longer treatment course in the reported cases. By contrast, other studies found unilateral ECT and BL ECT to be equally effective for mania [91,99]. One study compared the efficacy of ECT in treatment-resistant mania using unilateral and BL electrode placement. Results from the study showed that among 13 acute manic patients randomized to unilateral ECT, seven were responders and six were nonresponders; among 11 patients randomized to BL ECT, six were responders and five were nonresponders. There was no difference in treatment response associated with the anatomical positioning of the electrode placement in this study [99]. The strengths of this study is that the comparison was based on a medication-resistant sample and the study had a randomized design. Various factors might have attributed to the contradictory results from different reports in addition to study design, such as stimulus intensities, distance between the electrodes and sample selection [99].

A recent retrospective chart review of 65 bipolar patients who received ECT found robust response rates in all bipolar patients, including bipolar depressed, mania and mixed state. The number of ECT treatment was greater in mixed states compared with bipolar 
depression, suggesting mixed states might be more difficult to treat [100]. In a naturalistic study, 43 patients with rapid cycling were observed for 2-36 years following an index ECT course. The study found an acute course of ECT did not extinguish rapid cycling: 33 out of 43 patients continued to suffer from rapid cycling after only a brief improvement following an acute course of ECT. However, in the same study, two out of three patients who received continuation or maintenance ECT (M-ECT) were recovered at 2 years [101]. Some case reports stated that rapid cycling or mixed states can develop when off lithium during an ECT course [102]. For this reason, continuation of lithium during a course of ECT has been recommended, if twice-weekly treatment frequency is used. Studies have shown continuation of lithium during a course of ECT is safe and not associated with higher frequency of adverse effects $[103,104]$, when lithium is held 24 to $36 \mathrm{~h}$ before each ECT treatment session. Delirious mania with catatonic features is a severe form of mania, particularly in elderly patients with medical conditions. Fortunately, delirious mania and catatonia are highly responsive to ECT, which can be life saving (see the 'Catatonia' section).

Efficacy and effectiveness of ECT for medication-resistant mania became a focus in later research, after lithium and other neuroleptic drugs were used as first-line treatment for mania. Results from a critical literature review before 1994 found that $80 \%$ of medicationresistant manic patients achieved remission or, at least, had a marked clinical improvement following an acute course of ECT [105].

\section{Schizophrenia \& nonaffective psychotic spectrum disorders}

Schizophrenia is a serious debilitating mental illness that affects $1 \%$ of the population world-wide. In total, $65 \%$ of schizophrenia patients are also reported to experience at least one depressive episode at 20-year follow-up, with completed suicide rates of $10 \%$ at 10 years and $12 \%$ at 20 years [106]. Treatment options for schizophrenia were revolutionized by the introduction of pharmacotherapy in the 1950s. Lacking evidence of superiority of ECT over medication beyond an acute treatment phase [34], ECT is no longer used as a first-line treatment for chronic schizophrenia.

In 1985, a NIH Consensus Conference Panel recommended ECT for schizophrenia with acute onset and a shorter duration [20]. In 1990, the APA Task Force on ECT sanctioned the use of ECT for schizophrenia with prominent affective features or catatonia during exacerbations [14]. In the meantime, research also found that ECT was more effective in schizophrenia patients with excitement, delusions or delirium [33]. Tharyan and colleagues analyzed 26 randomized controlled trials (RCTs) trials from 1982 to 2004 and found that the ECT groups ( $n=392$; ten RCTs) had greater improvement, fewer relapses $(n=47$; two RCTs) and a greater likelihood of being discharged from a hospital $(n=98$; one RCT). However, the superiority of ECT over medication did not last after an acute course of treatment [36]. Another literature review suggested several factors might be associated with positive predictive value of ECT, such as delusions, hallucinations, affective or catatonic symptoms, absence of negative symptoms and a short duration of the current episode [107].

In recent years, clinical studies have focused on the treatment of medication-resistant schizophrenia. Results from a meta-analysis, involving 11 uncontrolled trials and four 
controlled trials, suggest the combination treatment of ECT and antipsychotic drugs is more effective than antipsychotic drug alone during an acute treatment phase [108]. This regimen may be an option for schizophrenia patients who need rapid symptom control or who are medication resistant [36]. Results from a naturalistic retrospective study suggest that augmentation of ECT with clozapine is safe [109] and may be effective in treatment of clozapine-resistant schizoaffective disorder [110]. Some authors suggested a repeat course of ECT or a longer initial course of ECT could be effective in clozapine-resistant schizophrenia patients [111]. National and international ECT practice guidelines currently recommend ECT as an augmentation strategy in treatment-refractory schizophrenia during acute exacerbation or continuation therapy [107].

\section{Catatonia}

Catatonia is a complex and heterogeneous syndrome, which consists of motor abnormalities that occur in association with changes in thought, mood and vigilance. The underlying etiology of catatonia is complex, including psychiatric illness, medical conditions and neuropsychiatric illnesses. Malignant catatonia is the most severe form of catatonia, and can be complicated by life-threatening medical conditions (e.g., dehydration, infection, stroke and deep venous thrombosis), autonomic instability and systemic organ failure [112]. Older adults are particularly susceptible to developing malignant catatonia [113]. It can be lethal if unrecognized or misdiagnosed $[114,115]$. ECT can be life saving for older adults who exhibited symptoms of malignant catatonia or acute catatonia $[113,116]$.

Catatonic symptoms are the most responsive to ECT, even more so than positive psychotic symptoms such as paranoid delusions or affective symptoms [117]. Elderly schizophrenia patients with intractable catatonia often experience medication resistance, medication intolerance or severe medical conditions, but can be treated effectively with acute ECT [118]. For schizophrenia patients with catatonia who relapsed after a positive response to acute ECT, a combination of C-ECT and neuroleptics has been shown to maintain improvements in symptoms [42,119]. Overall, elderly schizophrenia patients with intractable catatonia tolerated ECT well. Elderly patients with major depression have the highest prevalence of catatonia [120]. A naturalistic retrospective study found post-ECT treatment with lithium or antidepressants, such as tricyclics, bupropion and venlafaxine, but not selective serotonin reuptake inhibitors, had an excellent long-term outcome in elderly depressed patients with catatonia in a 4-year follow-up study [121]. Taylor and Abrams [122] reviewed 123 manic patients and found that $28 \%$ of them exhibited clinical signs of catatonia. Catatonic symptoms are associated with a more severe course in mania. Delirious manic patients often presented with dehydration, fever, elevated blood pressure and rapid heart rates [123]. ECT has been shown to be an effective and safe treatment for delirious mania with catatonic features [123].

Catatonic patients may initially present with worsening psychotic or behavioral symptoms, such as disorganization, confusion, extreme negativism, agitation and aggression. These patients can be at high risk of developing neuroleptic malignant syndrome (NMS) when receiving high potency neuroleptic drugs [124-127]. NMS is an uncommon adverse effect of antipsychotic drugs, but can lead to a life-threatening condition characterized by severe 
rigidity, tremor, fever, altered mental status, autonomic dysfunction, and elevated serum creatinine phosphokinase and white blood cell count. ECT is highly effective for NMS with significant clinical improvement after a few treatments [128]. Malignant catatonia and NMS both can be lethal but are reversible conditions, and have a good prognosis when adequate treatment is received promptly. The combination of ECT and lorazepam is highly effective for malignant catatonia secondary to NMS $[116,129,130]$. Some authors suggested that catatonia is a risk factor for NMS and proposed a hypothesis that NMS was a variant of malignant catatonia $[126,127,131,132]$. However, the link between NMS and malignant catatonia has not yet been confirmed.

Catatonic symptoms in elderly patients can be masked by concurrent medical and neurological conditions $[113,114,133,134]$, such as infectious disease (e.g., pneumonia and advanced syphilis), cardiovascular disease, cerebrovascular disease, renal failure, dementia with Lewy bodies or advanced Parkinson's disease, and dementia. Benzodiazepines are used as first-line treatment for mild-to-moderate catatonia [135]. Some authors have also suggested alternative medications for elderly catatonic patients, such as midazolam [136], memantine [137,138], topiramate [139] and amantadine [140]. ECT can be very effective for medication-resistant catatonia [134,135,141]. A combination of benzodiazepines and ECT has shown to be highly effective for NMS, malignant catatonia, and residual or refractory catatonia $[127,142]$.

\section{Parkinson's disease \& parkinsonism}

In addition to motor abnormality, patients with Parkinson's disease may also suffer from cognitive impairment, depression and anxiety. Pharmacotherapy is available for symptomatic treatment, but can be accompanied by side effects with both L-dopa and dopamine agonists, such as frank hallucinations (usually visual hallucinations), paranoia or delusions, mania and anxiety [143]. Atypical antipsychotics with fewer extra-pyramidal side effects, such as quetiapine and clozapine (off label), are often used to manage hallucinations and psychosis associated with dopaminergic treatment. ECT can be an effective treatment for patients who develop antiparkinsonian drug-induced psychosis and antipsychotic drugrefractory psychosis, or who have antipsychotic-induced intractable movement disorders despite discontinuing offending agents [144]. There is a higher prevalence of parkinsonism in elderly patients who were exposed to antipsychotic drugs [145-147]. Elderly patients with parkinsonism may lose self-care capacity, which may lead to drug treatment noncompliance. Case reports and series demonstrated that ECT was an effective treatment for antipsychoticinduced severe or persistent parkinsonism [148-151], suggesting that ECT may be an alternative treatment option if resolution of movement complications is required.

It is challenging to treat movement symptoms of idiopathic Parkinson's disease. As Parkinson's disease progresses, patients often suffer from 'on-off' phenomena, in which a higher or more frequent dose of antiparkinsonian drugs may be required during the 'on' period in order to maintain motor function during the 'off' period. However, high-dose antiparkinsonian drugs can cause significant adverse effects including psychiatric symptoms. In a placebo-controlled, double-blind study, 11 patients with severe Parkinson's disease and 'on-off' phenomena were treated with ECT or sham ECT. The results of the 
study showed that patients treated with real ECT had a significantly prolonged duration of 'on' period compared with those treated with sham ECT [152]. Relevant mechanisms of action may involve increasing the responsiveness of postsynaptic dopamine receptors $[152,153]$ and norepinephrine receptors [154], or dopamine transporter uptake [155]. In a pilot study, the use of ECT can prolong antiparkinsonian drug effects in Parkinson's disease with medication resistance [156]. M-ECT can be used as an adjunct treatment in some patients who are refractory to antiparkinsonian drugs [157].

The most common adverse effects of ECT in patients with Parkinson's disease are transient delirium, confusion, amnesia and cognitive impairment [156]. Dosage of L-dopa or dopamine agonists may need to be reduced to avoid post-ECT delirium and dyskinesis [158]. Overall, ECT is safe, effective, and well tolerated in elderly patients with Parkinson's disease and parkinsonism.

\section{Dementia}

Dementia is one of the major causes of disability in the geriatric population. Alzheimer's disease is the leading cause of dementia (60-70\%), followed by vascular dementia and dementia with Lewy bodies $[159,160]$. A total of $30-40 \%$ of demented patients have psychotic symptoms [161-163], 40-60\% have depressive symptoms [164,165], and 17-30\% have been diagnosed with major depression $[165,166]$. One out of six demented patients with major depression received ECT in a US national survey sample [167]. When underlying affective or psychotic symptoms are successfully treated with ECT, cognitive deficits may improve in some but not all demented patients with concurrent major depression $[168,169]$. A chart review from case reports and series in the 1980s found $30 \%$ (six out of 19 cases) of primary degenerative dementia with major depression had cognitive/ memory improvement after receiving ECT [168]. Other studies found that vascular dementia and clinically nondemented patients with MRI cerebral signal hyperintensity had cognitive decline or transient worsening after ECT, even though depression was successfully treated with ECT $[168,170]$.

Agitation, aggression and other behavioral disturbances are observed in up to $70 \%$ of patients with advanced dementia, and $25-35 \%$ of demented patients exhibit physical aggression or serious self-injurious behavior [171]. Atypical antipsychotic drugs are often used to manage severe behavioral disturbances and psychosis in demented patients [172174]. However, positive symptom improvement is not sizeable. In a 42-site, double-blind, placebo-controlled trial, 421 outpatients with Alzheimer's disease and psychosis, aggression or agitation were randomly assigned to receive olanzapine (mean dose: $5.5 \mathrm{mg}$ per day), quetiapine (mean dose: $56.5 \mathrm{mg}$ per day), risperidone (mean dose: $1.0 \mathrm{mg}$ per day) or placebo. Patients were followed for up to 36 weeks. Results from this study did not find that atypical antipsychotics were superior to placebo [175]. ECT, used as an alternative treatment when other treatment options were exhausted, has been shown to be effective in many uncontrolled case series, although the focal point of these studies was the benefit of ECT for short-term behavioral control [176,177]. Data supporting effectiveness of ECT for agitation/ aggression in demented elderly patients are limited. There has yet to be a comparison of the efficacy of ECT and antipsychotic drugs for treatment of demented patients with severe 
behavioral disturbances. ECT is currently considered to be a last resource for the treatment of agitation/aggression in patients with dementia.

Postictal prolonged confusion and worsened cognitive or memory function may occur in some demented patients who received BL ECT. However, these adverse effects were reported to be transient and reversible in most cases, ranging from a few days to a few months $[168,177,178]$. Older age, pre-existing cognitive impairment, coadministration ECT with other drugs and medical comorbidities may also be contributing factors. In general, ECT is safe and effective in treating patients with Alzheimer's dementia and severe behavioral disturbances, major depression, mania and psychosis [177].

\section{Stroke}

Prevalence of poststroke depression was $34 \%$ compared with $13 \%$ in older adults in the general population [179]. Most episodes of poststroke depression occur in the first 2 years after a cerebrovascular incident. The location of a lesion, particularly its proximity to the left frontal pole, has a profound impact on the frequency and severity of poststroke depression [180]. Poststroke mania is uncommon but can be clinically significant when lesions are within the right hemisphere [181]. A literature review of five randomized, placebocontrolled antidepressant trials for poststroke depression concluded that antidepressants could reduce the frequency and severity of crying or laughing episodes, but the efficacy of treating mood symptoms was very limited [182]. A retrospective study reviewed charts of 20 elderly patients who received ECT for poststroke depression and reported that $95 \%$ of patients improved with ECT and $15 \%$ of patients had transient interictal confusion or amnesia. No patient experienced acute exacerbation of pre-existing neurologic deficits in this study [183]. These findings indicate that ECT is generally well tolerated and effective for post-stroke depressed elderly patients, suggesting ECT should not be withheld from such patients.

\section{Pre-ECT evaluation}

A multidisciplinary approach to ECT is essential. Minimally, a treating psychiatrist, an ECT psychiatrist (who may be the same) and an anesthesiologist should evaluate the patient's current and past history of psychiatric illness, substance dependence, neuropsychiatric and medical conditions, and prior anesthesia. A baseline cognitive assessment, such as mini mental state examination is recommended. Patients with abnormal findings on neurological exam or neuropsychiatric testing should be referred for neuroimaging to rule out CNS pathology prior to ECT. For elderly patients who have sudden onset of psychiatric symptoms, personality change, neuropsychiatric conditions or significant medication resistance, brain imaging (e.g., MRI) should also be obtained. Baseline (prior to ECT) neurocognitive assessments (e.g., subjective and objective assessments of memory function) $[184,185]$ and global impact of ECT on mood or memory [186] can be very informative when evaluating post-ECT cognitive functioning, particularly in elderly patients who have pre-existing cognitive and memory impairment.

From a medical standpoint, any significant medical comorbidity should be evaluated in consultation. A medical specialist may need to be included in the multidisciplinary team. 
Current dental conditions (e.g., dentures, loose teeth and oral malformation) should be assessed in order to provide for a secure airway during ECT under general anesthesia. Basic laboratory tests prior to ECT should include complete blood count, basic metabolic panel and ECG. It is important to review current medications because they may have significant negative impact on the efficacy of ECT, patient safety and post-ECT recovery.

Written informed consent for ECT is the standard of care. ECT consent is locally regulated [187], particularly at the state level. ECT is not comparable with other life-saving medical procedures or treatment where consent can be obtained after the procedure or treatment in emergencies. If a patient does not have capacity for informed consent or there is no legal surrogate available, a court order may be an alternative. Consent can include both anesthesia procedures and the electrical stimulation. One informed consent is recommended for the acute phase of ECT while a separate consent is recommended for M-ECT. Informed consent should include risks and benefits comparable to a standard medical procedure consent form. The possibility of relapse and nonresponse should be addressed in the consent form, according to the nature of psychiatric pathology. An approximate number of treatments should be discussed with the patient or his surrogate, and this information can be included in the consent form. It is important to inform the patient or his surrogate that ECT consent can be withdrawn anytime.

\section{Maximizing ECT efficacy \& minimizing ECT side effects}

\section{Stimulus waveform}

Sine wave stimulus has been replaced by brief pulse stimulus since 2001, when professional organizations recommended discontinuing use of sine wave stimulation. Ultrabrief pulse was reintroduced in the late 1990s and in RCTs [188-190]. Ultrabrief pulse has been shown to be a more efficient method of delivering electrical dose regardless of anatomical positioning of electrode placement [188]. The use of ultrabrief pulse stimulation allows a wide range of effective stimulus dose on currently marketed devices (Table 1). There is growing data on the efficacy of ultrabrief pulse ECT, which appears to be effective while reducing adverse cognitive effects. It is currently not advised to practice ultra-brief BL ECT outside of research settings [191].

\section{Anesthesia}

Individual anesthetic agents and muscle relaxants have different benefit and side-effect profiles (Table 2). Methohexital has been a standard anesthetic agent for ECT. In contrast with methohexital and pentothal, propofol is less often used because propofol significantly shortens seizure duration, an observation that has prompted concern about effects on clinical outcomes. Subsequent studies have not shown reduced benefit with propofol. Succinylcholine is the most commonly used relaxant for ECT. However, it should be avoided if a patient has a history of malignant hyperthermia. Succinylcholine should not be used in a patient with atypical plasma cholinesterase. When needed, mivacurium is an alternative to succinylcholine. 


\section{Electrode placement}

Adverse cognitive effects associated with ECT can be persistent or even profound in some individuals. Anatomic positioning of the electrode placement is strongly associated with such cognitive deficits (Table 3 ). The severity and duration of retrograde memory impairment for autobiographical events are greater in patients receiving BL electrode placement than RUL electrode placement. Current data supporting the efficacy of bifrontal (BF) ECT are limited. A meta-analysis of eight RCTs, comparing efficacy and side effects of BF ECT to bitemporal or RUL ECT in depression, concluded that BF ECT is not more effective than BL or RUL ECT, but may have potential advantages over BL ECT for specific memory domains [192].

\section{Electrical stimulus \& seizure threshold}

Electrical signals have three variables: current, voltage and impedance (resistance). The relationship among these variables is: current $=$ voltage/resistance. Manipulation of both current and voltage can yield different stimulus intensity. The majority of available devices are constant-current devices, and all devices marketed in the USA are constant-current. The three predictive variables associated with seizure threshold are electrode placement, gender and age [193-195]. Seizure threshold is higher in BL electrode placement compared with unilateral electrode placement, in male patients and elderly patients. The stimulus dose is controlled by frequency of pulses, pulse width, duration of pulse train, and pulse amplitude. Each exerts unique neurobiological effects. Determining chronaxie is the standard method for determining optimal pulse width in neurostimualtion. Studies have shown the chronaxie for mammalian neuronal depolarization is $0.1-0.2 \mathrm{~ms}$. Standard ECT stimulus has had a pulse width between 0.5 and $2 \mathrm{~ms}$. Reduction of pulse width to physiologic range results in markedly reduced adverse effects while maintaining efficacy, except possibly BL electrode placement [190].

Traditionally, there was a widely held belief that the efficacy of ECT depended exclusively on whether or not a seizure was induced successfully; and stimulus dosing was responsible for cognitive side effects $[196,197]$. However, data from the controlled trials do not support this belief. The combinations of anatomical positioning of electrode placement and stimulus dose produce clinical efficacy, ranging from 20 to $80 \%$ in remission rates $[43,57,85]$, depending on how the treatment is performed. RUL electrode placement is particularly affected by stimulus dose, and a dose-response relationship exists up to a stimulus intensity of 8-12 times the seizure threshold. RUL ECT is less effective when an electrical dose is given close to seizure threshold [85]. A markedly suprathreshold dose improves the efficacy of RUL ECT to a level comparable to BL ECT, shortens the time to achieve clinical responses in both BL and unilateral ECT, but yields more short-term cognitive side effects [85,198].

\section{Titration \& dosing}

Empirical titration gives the most accurate estimation of seizure threshold currently available. Clinicians can calculate stimulus intensity based on the seizure threshold. The therapeutic stimulus intensity for unilateral ECT is $2.5-8$ times of seizure threshold, which 
produces the highest efficacy of ECT [44]. High-dosage RUL ECT $(6.0 \times \mathrm{ST})$ is as effective as high-dosage BL ECT $(2.5 \times \mathrm{ST})[43,44]$.

\section{ECT adverse effects \& management}

ECT carries risks, similar to all other medical procedures and treatments. The most common somatic side effects of ECT are headaches (48\%), muscle pain (15\%), dry mouth (23\%), nausea (23\%) and tiredness (73\%) [86]. The most common cognitive side effects are anterograde memory impairment $(41 \%)$ and confusion (37\%) [86]. The most concerning adverse effects related to ECT in elderly patients are cardiac or pulmonary complications, post-ECT delirium/confusion and persistent memory impairment. However, ECT has lower risk of complications than some forms of pharmacotherapy in elderly patients [14].

\section{Mortality \& medical complications}

Mortality rates associated with ECT have declined: 2-10 per 100,000 ECT treatments in the 1990s [199] and less than one per 100,000 ECT treatments in more recent studies [200,201]. Although there are no 'absolute' medical contraindication to ECT, the cardiovascular system and the CNS are two organ systems of critical importance when considering the medical risks of ECT. Specific conditions may increase the mortality risk associated with ECT, including a recent myocardial infarction, poorly compensated congestive heart failure, severe cardiac valvular disease, cerebral aneurysm, cerebrovascular malformation, brain lesions with increased intracranial pressure, a recent stroke/hemorrhage, severe chronic obstructive pulmonary disease, asthma, or pneumonia, and American Society of Anesthesiologists level 4 or 5 [187].

Older age per se is not a risk factor for mortality associated with ECT, although older adults may be at a greater risk because of a higher prevalence of medical comorbidity. A retrospective review of 2279 charts of patients who underwent 17,394 ECT at a single institution in a 13-year period reported that $21(0.92 \%)$ patients experienced complications at some time during the course of ECT, including five respiratory events (slow awakening, bronchospasm, apnea and respiratory arrest) and nine cardiac events. All of the patients who experienced cardiac event(s) had a history of cardiovascular disease prior to ECT. The majority of the cardiac events were arrhythmias (ventricular tachycardia, ventricular fibrillation and bradycardia with second degree heart block) and the rest had ischemic changes on ECG. One patient had asystole during ECT. There were no deaths, permanent injuries or disability related to ECT. The complication rate was $0.08 \%$ per ECT treatment [201]. A 3-year follow-up study reported 519 depressed patients who received ECT had a lower mortality than the antidepressant treatment group [21]. Therefore, early intervention and effective treatment of depression can be life saving. For elderly patients with severe depression and comorbid cardiac conditions who can not tolerate or are refractory to antidepressant treatment, ECT can be a fast and effective treatment for depression [63].

\section{Cardiac complications}

Rasmussen et al. described the normal cardiac physiology of ECT [202]. Initially, the parasympathetic nerve system is activated by electrical stimulus via the vagus nerve, and 
there is a sharp transient decreased HR and BP (10-15 s). Sympathetic nervous system output becomes predominant as soon as the seizure begins and a catecholamine surge occurs. The HR increases $20 \%$ or more, and the BP increases $30 \%$ or more during a seizure. Prudic and colleagues studied 34 patients who received ECT for major depression and found that those with high baseline HRs had smaller increases in peak postictal HR and BP; baseline HR predicts peak ECT postictal change of HR and BP, but not baseline BP [203].

Generally, vital signs return to baseline within minutes of the end of the ictal period. Healthy individuals can tolerate these transient autonomic changes without adverse outcome. However, when electrical stimulus does not have sufficient intensity to cause generalized seizure, some patients may develop bradycardia or even asystole due to persistent parasympathetic effect. A low dose of atropine $(0.2-0.6 \mathrm{mg})$ can be sufficient to prevent severe bradycardia and asystole, particularly during seizure threshold titration sessions. A higher dose of atropine should not be administered to elderly patients, because it might contribute to postictal delirium or confusion, and urinary retention [202]. Glycopyrrolate (0.1-0.03 mg intravenously) can also effectively prevent asystole during titration. Although rare, supraventricular tachycardia is more commonly found with use of anticholinergic agents [204].

Although both the prevalence and severity of hypertension increase markedly with advancing age [205], the transient autonomic changes during ECT are well tolerated by elderly patients with controlled hypertension [206]. For patients who have uncontrolled hypertension, the condition should be treated before receiving ECT treatment [207]. Shortacting $\beta$-blockers, such as esmolol and labetalol, have been used in attenuating HR and BP responses to sharply increased sympathetic output during ECT [208]. However, pretreatment with low-dose esmolol had led to decrease seizure duration that reduced the efficacy of ECT in a double-blind, placebo-controlled study [209]. A retrospective study found no evidence that ECT caused sustainably increased BP, either in hypertensive or nonhypertensive patients during the course of ECT [210].

When a patient has pre-existing cardiovascular conditions, such as ischemic heart disease, congestive heart failure or valvular disease, cardiac compromise may occur during ECT. Zielinski and colleagues compared the rate of complications of ECT between 40 elderly depressed patients with cardiac disease and 40 matched depressed patients without cardiac disease [211]. The study found that the patients with cardiac disease had a significantly higher rate of cardiac complications (minor and major) during ECT than the comparison group without cardiac disease. All ischemic events occurred in patients with known ischemic heart disease or myocardial infraction. There was no death in this study. Preexisting cardiac abnormality strongly predicted the type of cardiac complication that may occur with ECT. The study also found no significant difference in age, number of ECT per patient, anesthetic used or electrode placement, comparing the subgroups with major, minor or no complications.

For patients with less than $25 \%$ ejection fraction, complication rates increase dramatically. Treatment for congestive heart failure before ECT should be optimized. Stern and colleagues described three patients who had congestive heart failure with low ejection 
fraction (26, 25 and 20\%) [212]. These patients received optimal treatment of congestive heart failure before ECT. All three cases were successfully treated with ECT without major complications during and post-ECT. The authors proposed a protocol for patients with low cardiac output: administration of regular cardiac medications 60-90 min before ECT; a 5mg nitroglycerine adhesive plaster $30 \mathrm{~min}$ before ECT; sublingual nifedipine 20-30 min before ECT; intravenous labetalol (5-15 mg) 5-10 min before ECT, avoidance of anticholinergic medications. Prophylactic intravenous $\beta$-blocker has been suggested for patients who had marked hypertension during previous ECT sessions (e.g., systolic BP over $180 \mathrm{mmHg}$ ) or a HR greater than 100 beats per minute, in a retrospective chart review study [213]. Patients with large aneurysms or severe valvular heart disease may need surgical treatment to correct the anatomic problems before ECT. There are reports that elderly patients with unrepaired small abdominal aortic aneurysms (range from 3.0 to $5.2 \mathrm{~cm}$ ), descending aortic aneurysm and aortic valve stenosis ( 4.0 ) under rigorous medical management can be successfully treated with ECT [214-216].

Takotsubo cardiomyopathy is an acute and reversible ventricular dysfunction with abnormal ECG findings, such as ST-T and QTc changes, in the absence of significant coronary artery disease. It is typically mediated by catecholamines. During an ictal phase of ECT, when sympathetic output significantly increases, catecholamines also markedly increase. There are a number of case reports in the literature on Takotsubo cardiomyopathy associated with ECT in postmenopausal women [217-222]. The abnormalities are usually reversible in a few weeks. Some authors suggest administering $\beta$-blockers $[218,219]$ because it has cardiac protective effect if ECT is retried. Early recognition and treatment of Takotsubo cardiomyopathy, with consultation from cardiology and anesthesiology, may allow ECT to be continued. In summary, ECT can be given with relative safety to elderly patients with cardiovascular disease.

\section{Pulmonary complications}

Pre-ECT treatment of chronic obstructive pulmonary disease to optimize lung capacity is essential. Theophylline, although seldom used in current practice, has been associated with higher risk of prolonged seizures during ECT, even within therapeutic blood levels [223]. For patients with history or family history of pseudocholinesterase deficiency, prolonged apnea may occur during ECT, when succinylcholine is used as a muscle relaxant [224]. Nondepolarizing muscle relaxants can be used alternatively. In a retrospective chart review, elderly patients who had active asthma underwent ECT for severe depression. It was concluded that ECT was safe and well tolerated, although four patients experienced five transient but reversible asthma exacerbations [225]. Based on individual needs, patients with active asthma should use their inhalers shortly before ECT treatment.

\section{Postictal delirium \& confusion}

Benzodiazepine withdrawal, coadministration of ECT with bupropion [226], lithium [227], dopaminergic drugs (e.g., L-dopa) [228] and theophylline [223] may contribute to post-ECT delirium and prolonged confusion. Elderly patients with underlying neuropsychiatric conditions, such as cognitive impairment [229], Parkinson's disease/parkinsonism $[228,230]$, dementia $[231,232]$ and stroke $[233,234]$ are at a higher risk of developing 
delirium and confusion immediately after ECT. A study compared the incidence of ECTinduced delirium in 14 depressed elderly patients who had a history of stroke with 14 depressed elderly controls (without a history of cerebrovascular accident) and found no difference in the overall incidence rates of delirium between the two groups (28.5\%) [235]. Some patients who had a recent cerebrovascular accident involving the caudate nucleus appeared more likely to develop delirium in one study [234].

Reducing a half of the regular dosage of antiparkinsonian drug before initiating ECT might prevent post-ECT delirium related to dopamine toxicity [228]. Some authors suggested that done-pezil was helpful in shortening the duration of delirium and agitation [236]. Others suggested intravenous benzodiazepines, propofol and higher doses of succinylcholine might decrease the severity of post-ECT delirium [229,237,238]. In general, delirium and confusion are transient and reversible $[183,235]$. ECT may be withheld when a patient has prolonged post-ECT confusion or becomes delirious. Further investigation (e.g., neuroimaging and electrolytes) may be needed in elderly patients with pre-existing medical illness and cerebrovascular disease. Although adverse cerebrovascular events due to increased intracranial pressure associated with increased cerebral blood flow during ECT are rare, the appearance of delirium in elderly patients should be monitored very closely and treated without delay. If the condition does not resolve within a reasonable time frame, neurology or neurosurgery consultation should be considered.

\section{Cognitive side effects}

Prudic and colleagues conducted a prospective, naturalistic study on the effectiveness of ECT involved 347 patients at seven hospitals in metropolitan New York City (NY, USA) [185]. The study assessed patients at baseline, immediately post-ECT, and 6 months postECT, and found no difference in the efficacy of ECT but marked differences in cognitive impairment associated with different techniques. Sine wave had worse cognitive impairment compared with brief pulse; BL electrode placement had greater deficits at post-ECT than RUL electrode placement; retrograde amnesia for autobiographical information was greater with BL electrode placement than RUL electrode placement in 6-month follow-up. On the other hand, most patients who received RUL ECT, showed cognitive improvement compared with baseline by 6 months. In addition, higher stimulus intensity over seizure threshold is associated with more cognitive side effects. In a RCT, ultrabrief pulse ECT had a better post-ECT autobiographical and anterograde memory side-effect profile than brief pulse ECT [239].

The frequency of the ECT, but not the total number of ECT treatments in a lifetime, predicts the degree of cognitive impairment post-ECT [240]. Older age, female gender and low baseline cognitive performance increase the degree of risk for adverse cognitive impairment with ECT [241]. Presence of depressive symptoms increases complaints of cognitive difficulties in many settings. Some authors suggest that side effects of ECT are mainly depressive phenomena and are independent of age [242]. Brodaty and colleagues assessed 81 patients (mean age 7 years) with major depression prospectively pre-ECT, immediately post-ECT and 1-3 years later [243]. Tests on anterograde memory, reaction time, attention, concentration, speed of cognitive processing and fluency were used; there were no tests on 
retrograde memory function. The study did not find impairment on these tests more pronounced directly after ECT or at follow-up in older patients, suggesting the improvement of depression in post-ECT correlated with reduction of side effect burden. Assessing elderly depressed patients' cognitive functioning is complex and multifactorial. At this time, the effect of ECT in elderly patients' cognition remains incompletely described.

\section{C-ECT \& M-ECT}

C-ECT may be required in the first 6 months after a remission with acute ECT treatment. The recommended post-ECT continuation pharmacotherapy is combined lithium and antidepressant. If a patient fails standard pharmacotherapy following a successful course of ECT, C-ECT should be considered in order to decrease the likelihood of relapse [244]. The goal of C-ECT is to prevent relapse while M-ECT, beginning 6 months after C-ECT, is used to prevent recurrence. Kellner and colleagues [245] evaluated the comparative efficacy of CECT and the combination of lithium plus nortriptyline (continuation pharmacotherapy) after a successful acute ECT course. There were 201 depressed patients in the study, including 66 elderly patients. This multisite randomized trial found that both C-ECT and continuation pharmacotherapy reduced relapse rates, and had no age differences in the rates of response and symptom remission [245].

Medication resistance during the index episode predicts a higher rate of relapse [59]. A retrospective chart review of 58 elderly patients with recurrent MDD or bipolar depression showed that rates of admission to hospital fell by $53 \%$ in number and $79 \%$ in duration in the 2 years after continuation-maintenance ECT began, and the rates of admission fell by $90 \%$ in number and $97 \%$ in duration within the actual treatment period [246]. A recent literature review concluded that M-ECT is as effective as maintenance medication after a successful course of ECT and is well tolerated in elderly depressed patients [247]. There are no established C-ECT and M-ECT treatment schedules. Usually, an ECT taper bridges the acute treatment to the continuation treatment. Typically, weekly ECT is given during the first month after acute treatment; then tapered to every other week ECT in the following 1 or 2 months; and tapered further to monthly ECT thereafter. The frequency of C-ECT or MECT should be modified to meet an individual patient's needs.

Besides affective disorders, M-ECT is utilized in treatment-resistant schizophrenia. A controlled study reported the combined treatment with ECT and antipsychotic drugs was superior to ECT alone or medication alone in relapse prevention [248]. M-ECT has been shown to be effective in preventing relapse in catatonic schizophrenia patients [42]. For patients who have severe Parkinson's disease comorbid with affective disorder, M-ECT can benefit both illnesses. In elderly patients, the most concerning side effects of ECT are anterograde and retrograde amestic memory impairment. A placebo-controlled study of cognitive function related to ECT suggested that the administration of a large number of ECT (over 100 life time ECT treatments), spaced over several courses, did not result in long-term cognitive impairment [240]. Overall, C-ECT and M-ECT are effective and should be considered for elderly patients who can not tolerate medications and who are medicationresistent, treatment refractory, or have severe medical comorbidities, limiting the use of pharmacotherapy. 


\section{Conclusion \& future perspective}

Currently, ECT is still the most widely available nonpharmacologic treatment procedure for severe mental illness, although newer neuromodulation therapies are being developed. These newer brain stimulation modalities include more invasive procedures, such as vagal nerve stimulation, deep brain stimulation and epidural cortical stimulation, and less invasive procedures, such as transcranial magnetic stimulation, transcranial direct current stimulation and magnetic seizure therapy (MST). Only transcranial magnetic stimulation and vagal nerve stimulation are US FDA approved. As discussed elsewhere in this review, the cardiac and cognitive side-effect profiles of ECT are the major concerns of practicing ECT in the geriatric population. MST is an experimental brain stimulation technique that involves a magnetically induced seizure. MST presumably has a better localization of the site of initiation and focalization of propagation [249], which could cause fewer cognitive side effects and possibly have less impact on parasympathetic and sympathetic outflow, which cause HR and BP fluctuation [250]. However, the efficacy of MST in the treatment of depression has not been established [251], although MST has been found to be associated with rapid reorientation and intact anterograde and retrograde memory [252]. Elderly patients may benefit from MST because of its favorable side-effect profile compared with ECT if antidepressant effect of MST is comparable with or superior to ECT, and the treatment becomes FDA approved.

Adverse cognitive effects are a major factor limiting the use of ECT. Work continues on reducing cognitive adverse effects, and placing electrodes near specific anatomic areas of the brain, which are functionally related to mood and behavior while sparing areas associated with learning, memory and cognition. FEAST trial [301] is an example. Various strategies for improving cognitive and memory deficits following ECT, such as Cognitive Training for Memory Deficits Associated with ECT [302], are based on the evidence that cognitive remediation improves memory performance in epilepsy. As mentioned earlier in this review, a marked suprathreshold dose improves efficacy of ECT, but yields more severe acute or short-term cognitive side effects. Future clinical and research studies should also focus on how and when to utilize ECT as a powerful synergistic therapy, to enhance other biological therapies and psychotherapy, and prevent symptom relapse or recurrence.

\section{Acknowledgments}

This work was supported by grant T32 MH 020004 from the National Institute of Mental Health (NIMH).

\section{References}

Papers of special note have been highlighted as:

- of interest

1. Leiknes KA, Jarosh-von Schweder L, Hoie B. Contemporary use and practice of electroconvulsive therapy worldwide. Brain Behav. 2012; 2(3):283-344. [PubMed: 22741102]

2. Hermann RC, Dorwart RA, Hoover CW, Brody J. Variation in ECT use in the United States. Am.. J. Psychiatry. 1995; 152(6):869-875. [PubMed: 7755116]

3. Rosenbach ML, Hermann RC, Dorwart RA. Use of electroconvulsive therapy in the Medicare population between 1987 and 1992. Psychiatr. Serv. 1997; 48(12):1537-1542. [PubMed: 9406260] 
4. Weiner RD, Prudic J. Electroconvulsive therapy in the United States: how often is it used? Biol. Psychiatry. 2013; 73(2):105-106. [PubMed: 23245949] . - Regardless of utilization rate, it is clear that electroconvulsive therapy (ECT) remains the most effective and rapidly active treatment modality for use in the management of certain mental disorders, most notably major depression. It is particularly impressive that this advantage of ECT has remained in spite of an ever-increasing array of psychopharmacologic and psychotherapeutic alternatives.

5. Thompson JW, Weiner RD, Myers CP. Use of ECT in the United States in 1975, 1980, and 1986. Am. J. Psychiatry. 1994; 151(11):1657-1661. [PubMed: 7943457]

6. Roose SP, Sackeim HA, Krishnan KR, et al. Old-Old Depression Study Group. Antidepressant pharmacotherapy in the treatment of depression in the very old: a randomized, placebo-controlled trial. Am. J. Psychiatry. 2004; 161(11):2050-2059. [PubMed: 15514406]

7. Schatzberg AF, Kraemer HC. Use of placebo control groups in evaluating efficacy of treatment of unipolar major depression. Biol. Psychiatry. 2000; 47(8):736-744. [PubMed: 10773182]

8. Roose SP, Sackeim HA. Clinical trials in late-life depression: revisited. Am. J. Geriatr. Psychiatry. 2002; 10(5):503-505. [PubMed: 12213683]

9. Roose SP, Schatzberg AF. The efficacy of antidepressants in the treatment of late-life depression. J. Clin. Psychopharmacol. 2005; 25 Suppl. 1(4):S1-S7. [PubMed: 16027554]

10. Sneed JR, Culang-Reinlieb ME, Brickman AM, et al. MRI signal hyperintensities and failure to remit following antidepressant treatment. J. Affect. Disord. 2011; 135(1-3):315-320. [PubMed: 21802739]

11. Alexopoulos GS, Murphy CF, Gunning-Dixon FM, et al. Microstructural white matter abnormalities and remission of geriatric depression. Am. J. Psychiatry. 2008; 165(2):238-244. [PubMed: 18172016]

12. Navarro V, Gastó C, Lomeña F, et al. Prognostic value of frontal functional neuroimaging in lateonset severe major depression. Br. J. Psychiatry. 2004; 184:306-311. [PubMed: 15056574]

13. Taylor WD, Steffens DC, MacFall JR, et al. White matter hyperintensity progression and late-life depression outcomes. Arch. Gen. Psychiatry. 2003; 60(11):1090-1096. [PubMed: 14609884]

14. American Psychiatric Association. Task Force on Electroconvulsive Therapy. The practice of ECT: recommendations for treatment, training and privileging. Convuls. Ther. 1990; 6(2):85-120. [PubMed: 11659302]

15. Benbow SM. The role of electroconvulsive therapy in the treatment of depressive illness in old age. Br. J. Psychiatry. 1989; 155:147-152. [PubMed: 2688790]

16. Tew JD Jr, Mulsant BH, Haskett RF, et al. Acute efficacy of ECT in the treatment of major depression in the old-old. Am. J. Psychiatry. 1999; 156(12):1865-1870. [PubMed: 10588398] . Despite a higher level of physical illness and cognitive impairment, even the oldest patients with severe major depression tolerate ECT in a manner similar to that of younger patients, and demonstrate a similar or better acute response.

17. Endler NS. The origins of electroconvulsive therapy (ECT). Convuls. Ther. 1988; 4(1):5-23. [PubMed: 11940939]

18. Slater ET. Evaluation of electric convulsion therapy as compared with conservative methods of treatment in depressive states. J. Ment. Sci. 1951; 97(408):567-569. [PubMed: 14861614]

19. Karagulla S. Evaluation of electric convulsion therapy as compared with conservative methods of treatment in depressive states. J. Ment. Sci. 1950; 96(405):1060-1091. [PubMed: 14804044]

20. Consensus conference. Electroconvulsive therapy. JAMA. 1985; 254(15):2103-2108. [PubMed: 4046138]

21. Avery D, Winokur G. Mortality in depressed patients treated with electroconvulsive therapy and antidepressants. Arch. Gen. Psychiatry. 1976; 33(9):1029-1037. [PubMed: 962487]

22. Kral VA. Somatic therapies in older depressed patients. J. Gerontol. 1976; 31(3):311-313. [PubMed: 1270765]

23. Winslade WJ, Liston EH, Ross JW, Weber KD. Medical, judicial, statutory regulation of ECT in the United States. Am. J. Psychiatry. 1984; 141(11):1349-1355. [PubMed: 6496778]

24. APA Task Force report calls ECT a valuable treatment for some affective disorders. Hosp. Community Psychiatry. 1979; 30(2):144-147. [PubMed: 759294] 
25. Runck B. NIMH report. Consensus panel backs cautious use of ECT for severe disorders. Hosp. Community Psychiatry. 1985; 36(9):943-946. [PubMed: 4065852]

26. Fink M. The practice of ECT: recommendations for treatment, training, and privileging background. Convuls. Ther. 1990; 6(2):82-84. [PubMed: 11659301]

27. Janicak PG, Davis JM, Gibbons RD, Ericksen S, Chang S, Gallagher P. Efficacy of ECT: a metaanalysis. Am. J. Psychiatry. 1985; 142(3):297-302. [PubMed: 3882006]

28. Folkerts HW, Michael N, Tölle R, Schonauer K, Mücke S, Schulze-Mönking H. Electroconvulsive therapy vs. paroxetine in treatment-resistant depression - a randomized study. Acta Psychiatr. Scand. 1997; 96(5):334-342. [PubMed: 9395150]

29. Gangadhar BN, Kapur RL, Kalyanasundaram S. Comparison of electroconvulsive therapy with imipramine in endogenous depression: a double blind study. Br. J. Psychiatry. 1982; 141:367-371. [PubMed: 6756530]

30. Small JG, Klapper MH, Kellams JJ, et al. Electroconvulsive treatment compared with lithium in the management of manic states. Arch. Gen. Psychiatry. 1988; 45(8):727-732. [PubMed: 2899425]

31. Mukherjee S, Sackeim HA, Schnur DB. Electroconvulsive therapy of acute manic episodes: a review of 50 years' experience. Am. J. Psychiatry. 1994; 151(2):169-176. [PubMed: 8296883]

32. Aziz R, Lorberg B, Tampi RR. Treatments for late-life bipolar disorder. Am. J. Geriatr. Pharmacother. 2006; 4(4):347-364. [PubMed: 17296540]

33. Fink M, Sackeim HA. Convulsive therapy in schizophrenia? Schizophr. Bull. 1996; 22(1):27-39. [PubMed: 8685661]

34. Abraham KR, Kulhara P. The efficacy of electroconvulsive therapy in the treatment of schizophrenia. A comparative study. Br. J. Psychiatry. 1987; 151:152-155. [PubMed: 3318990]

35. Brandon S, Cowley P, McDonald C, Neville P, Palmer R, Wellstood-Eason S. Leicester ECT trial: results in schizophrenia. Br. J. Psychiatry. 1985; 146:177-183. [PubMed: 3884080]

36. Tharyan P, Adams CE. Electroconvulsive therapy for schizophrenia. Cochrane Database Syst. Rev. 2005; 2:CD000076. [PubMed: 15846598]

37. Kupchik M, Spivak B, Mester R, et al. Combined electroconvulsive-clozapine therapy. Clin. Neuropharmacol. 2000; 23(1):14-16. [PubMed: 10682225]

38. Goswami U, Kumar U, Singh B. Efficacy of electroconvulsive therapy in treatment resistant schizophreinia : a double-blind study. Indian J. Psychiatry. 2003; 45(1):26-29. [PubMed: 21206809]

39. Deshmukh DK, Sethna KJ, Nagesh RP, Haridas RM, Patankar SV. A comparative study to evaluate the efficacy of spaced v/s daily electroconvulsive therapy in schizophrenia. Indian J. Psychiatry. 1980; 22(4):366-367. [PubMed: 22058500]

40. Janakiramaiah N, Subbakrishan DK. Ect-chlorpromazine combination compared with chlorpromazine only in schizophrenia. Indian J. Psychiatry. 1981; 23(3):230-233. [PubMed: 22058544]

41. Natani GD, Gautam S, Gehlot PS. Comparison of three treatment regimes in schizophrenia. Indian J. Psychiatry. 1983; 25(4):306-311. [PubMed: 21847308]

42. Suzuki K, Awata S, Takano T, Ebina Y, Iwasaki H, Matsuoka H. Continuation electroconvulsive therapy for relapse prevention in middle-aged and elderly patients with intractable catatonic schizophrenia. Psychiatry Clin. Neurosci. 2005; 59(4):481-489. [PubMed: 16048455]

43. Sackeim HA, Prudic J, Devanand DP, et al. A prospective, randomized, double-blind comparison of bilateral and right unilateral electroconvulsive therapy at different stimulus intensities. Arch. Gen. Psychiatry. 2000; 57(5):425-434. [PubMed: 10807482] . Right unilateral ECT at high dosage is as effective as a robust form of bilateral ECT, but produces less severe and persistent cognitive effects.

44. McCall WV, Reboussin DM, Weiner RD, Sackeim HA. Titrated moderately suprathreshold vs fixed high-dose right unilateral electroconvulsive therapy: acute antidepressant and cognitive effects. Arch. Gen. Psychiatry. 2000; 57(5):438-444. [PubMed: 10807483]

45. Sackeim HA, Haskett RF, Mulsant BH, et al. Continuation pharmacotherapy in the prevention of relapse following electroconvulsive therapy: a randomized controlled trial. JAMA. 2001; 285(10): 1299-1307. [PubMed: 11255384] . Indicates that without active treatment, virtually all remitted 
patients relapse within 6 months of stopping ECT. Monotherapy with nortriptyline has limited efficacy. The combination of nortriptyline and lithium is more effective, but the relapse rate is still high, particularly during the first month of continuation therapy.

46. Prudic J, Haskett RF, McCall WV, et al. Pharmacological strategies in the prevention of relapse after electroconvulsive therapy. J. ECT. 2013; 29(1):3-12. [PubMed: 23303417] . - Starting an antidepressant medication during ECT does not affect relapse. Nortriptyline and venlafaxine were equally effective in prolonging remission, although relapse rates after ECT are substantial despite intensive pharmacology.

47. Mathers CD, Loncar D. Projections of global mortality and burden of disease from 2002 to 2030. PLoS Med. 2006; 3(11):e442. [PubMed: 17132052]

48. Bing EG, Burnam MA, Longshore D, et al. Psychiatric disorders and drug use among human immunodeficiency virus-infected adults in the United States. Arch. Gen. Psychiatry. 2001; 58(8): 721-728. [PubMed: 11483137]

49. Nicholson A, Kuper H, Hemingway H. Depression as an aetiologic and prognostic factor in coronary heart disease: a meta-analysis of 6362 events among 146538 participants in 54 observational studies. Eur. Heart J. 2006; 27(23):2763-2774. [PubMed: 17082208]

50. González HM, Tarraf W, Whitfield KE, Vega WA, et al. The epidemiology of major depression and ethnicity in the United States. J. Psychiatr. Res. 2010; 44(15):1043-1051. [PubMed: 20537350]

51. Diagnosis and treatment of depression in late life. NIH Consensus Development Conference. November 4-6, 1991. NIH Consens. Statement. 1991; 9(3):1-27.

52. Penninx BW, Geerlings SW, Deeg DJ, van Eijk JT, van Tilburg W, Beekman AT. Minor and major depression and the risk of death in older persons. Arch. Gen. Psychiatry. 1999; 56(10):889895. [PubMed: 10530630]

53. Kay DW, Bergmann K. Physical disability and mental health in old age. A follow-up of a random sample of elderly people seen at home. J. Psychosom. Res. 1966; 10(1):3-12. [PubMed: 5949377]

54. Stanley WJ, Fleming H. A clinical comparison of phenelzine and electro-convulsive therapy in the treatment of depressive illness. J. Ment. Sci. 1962; 108:708-710. [PubMed: 13983404]

55. McDonald IM, Perkins M, Marjerrison G, Podilsky M. A controlled comparison of amitriptyline and electroconvulsive therapy in the treatment of depression. Am. J. Psychiatry. 1966; 122(12): 1427-1431. [PubMed: 5326021]

56. Janakiramaiah N, Gangadhar BN, Naga Venkatesha Murthy PJ, Harish MG, Subbakrishna DK, Vedamurthachar A. Antidepressant efficacy of Sudarshan Kriya Yoga (SKY) in melancholia: a randomized comparison with electroconvulsive therapy (ECT) and imipramine. J. Affect. Disord. 2000; 57(1-3):255-259. [PubMed: 10708840]

57. Husain MM, Rush AJ, Fink M, et al. Speed of response and remission in major depressive disorder with acute electroconvulsive therapy (ECT): a Consortium for Research in ECT (CORE) report. J. Clin. Psychiatry. 2004; 65(4):485-491. [PubMed: 15119910]

58. Rush AJ, Trivedi M, Fava M. Depression, IV: STAR*D treatment trial for depression. Am. J. Psychiatry. 2003; 160(2):237. [PubMed: 12562566]

59. Prudic J, Haskett RF, Mulsant B, et al. Resistance to antidepressant medications and short-term clinical response to ECT. Am. J. Psychiatry. 1996; 153(8):985-992. [PubMed: 8678194]

60. Khalid N, Atkins M, Tredget J, Giles M, Champney-Smith K, Kirov G. The effectiveness of electroconvulsive therapy in treatment-resistant depression: a naturalistic study. J. ECT. 2008; 24(2):141-145. [PubMed: 18580559]

61. Dombrovski AY, Mulsant BH, Haskett RF, Prudic J, Begley AE, Sackeim HA. Predictors of remission after electroconvulsive therapy in unipolar major depression. J. Clin. Psychiatry. 2005; 66(8):1043-1049. [PubMed: 16086621]

62. O'Connor MK, Knapp R, Husain M, et al. The influence of age on the response of major depression to electroconvulsive therapy: a C.O.R.E. Report. Am. J. Geriatr. Psychiatry. 2001; 9(4): 382-390. [PubMed: 11739064]

63. Tomac TA, Rummans TA, Pileggi TS, Li H. Safety and efficacy of electroconvulsive therapy in patients over age 85. Am. J. Geriatr. Psychiatry. 1997; 5(2):126-130. [PubMed: 9106376] 
64. Williams JH, O'Brien JT, Cullum S. Time course of response to electroconvulsive therapy in elderly depressed subjects. Int. J. Geriatr. Psychiatry. 1997; 12(5):563-566. [PubMed: 9193966]

65. Philibert RA, Richards L, Lynch CF, Winokur G. Effect of ECT on mortality and clinical outcome in geriatric unipolar depression. J. Clin. Psychiatry. 1995; 56(9):390-394. [PubMed: 7665536]

66. Parker G, Roy K, Hadzi-Pavlovic D, Wilhelm K, Mitchell P. The differential impact of age on the phenomenology of melancholia. Psychol. Med. 2001; 31(7):1231-1236. [PubMed: 11681549]

67. Fink M, Rush AJ, Knapp R, et al. Consortium for Research in ECT (CORE) Study Group. DSM melancholic features are unreliable predictors of ECT response: a CORE publication. J. ECT. 2007; 23(3):139-146. [PubMed: 17804986]

68. Prudic J, Devanand DP, Sackeim HA, Decina P, Kerr B. Relative response of endogenous and nonendogenous symptoms to electroconvulsive therapy. J. Affect. Disord. 1989; 16(1):59-64. [PubMed: 2521653]

69. Cronholm B, Ottosson JO. Experimental studies of the therapeutic action of electroconvulsive therapy in endogenous depression. The role of the electrical stimulation and of the seizure studied by variation of stimulus intensity and modification by lidocaine of seizure discharge. Convuls. Ther. 1996; 12(3):172-194. [PubMed: 8872406]

70. Meyers BS, Kalayam B, Mei-Tal V. Late-onset delusional depression: a distinct clinical entity? J. Clin. Psychiatry. 1984; 45(8):347-349. [PubMed: 6746580]

71. Roose SP, Glassman AH, Walsh BT, Woodring S, Vital-Herne J. Depression, delusions, and suicide. Am. J. Psychiatry. 1983; 140(9):1159-1162. [PubMed: 6614220]

72. Johnson J, Horwath E, Weissman MM. The validity of major depression with psychotic features based on a community study. Arch. Gen. Psychiatry. 1991; 48(12):1075-1081. [PubMed: 1845225]

73. Baldwin RC. Delusional and non-delusional depression in late life. Evidence for distinct subtypes. Br. J. Psychiatry. 1988; 152:39-44. [PubMed: 3167375]

74. O'Leary D, Gill D, Gregory S, Shawcross C. Which depressed patients respond to ECT? The Nottingham results. J. Affect. Disord. 1995; 33(4):245-250. [PubMed: 7790678]

75. Petrides G, Fink M, Husain MM, et al. ECT remission rates in psychotic versus nonpsychotic depressed patients: a report from CORE. J. ECT. 2001; 17(4):244-253. [PubMed: 11731725]

76. Prudic J, Sackeim HA, Devanand DP. Medication resistance and clinical response to electroconvulsive therapy. Psychiatry Res. 1990; 31(3):287-296. [PubMed: 1970656]

77. Klap R, Unroe KT, Unutzer J. Caring for mental illness in the United States: a focus on older adults. Am. J. Geriatr. Psychiatry. 2003; 11(5):517-524. [PubMed: 14506085]

78. Koenig HG, Blazer DG. Epidemiology of geriatric affective disorders. Clin. Geriatr. Med. 1992; 8(2):235-251. [PubMed: 1600475]

79. Sajatovic M, Blow FC, Ignacio RV, Kales HC. New-onset bipolar disorder in later life. Am. J. Geriatr. Psychiatry. 2005; 13(4):282-289. [PubMed: 15845753]

80. Depp CA, Jeste DV. Bipolar disorder in older adults: a critical review. Bipolar Disord. 2004; 6(5): 343-367. [PubMed: 15383127]

81. D’Souza R, Rajji TK, Mulsant BH, Pollock BG. Use of lithium in the treatment of bipolar disorder in late-life. Curr. Psychiatry Rep. 2011; 13(6):488-492. [PubMed: 21847537]

82. Young RC, Gyulai L, Mulsant BH, et al. Pharmacotherapy of bipolar disorder in old age: Review and recommendations. Am. J. Geriatr. Psychiatry. 2004; 12(4):342-357. [PubMed: 15249272]

83. Sproule BA, Hardy BG, Shulman KI. Differential pharmacokinetics of lithium in elderly patients. Drugs Aging. 2000; 16(3):165-177. [PubMed: 10803857]

84. Dierckx B, Heijnen WT, van den Broek WW, Birkenhäger TK. Efficacy of electroconvulsive therapy in bipolar versus unipolar major depression: a meta-analysis. Bipolar Disord. 2012; 14(2): 146-150. [PubMed: 22420590]

85. Sackeim HA, Prudic J, Devanand DP, et al. Effects of stimulus intensity and electrode placement on the efficacy and cognitive effects of electroconvulsive therapy. N. Engl. J. Med. 1993; 328(12): 839-846. [PubMed: 8441428] 
86. Sackeim HA, Ross FR, Hopkins N, Calev L, Devanand DP. Subjective side effects acutely following ECT: associations with treatment modality and clinical response. Convuls. Ther. 1987; 3(2):100-110. [PubMed: 11940903]

87. Daly JJ, Prudic J, Devanand DP, et al. ECT in bipolar and unipolar depression: differences in speed of response. Bipolar Disord. 2001; 3(2):95-104. [PubMed: 11333069]

88. Agarkar S, Hurt S, Lisanby S, Young RC. ECT use in unipolar and bipolar depression. J. ECT. 2012; 28(3):e39-e40. [PubMed: 22914639]

89. Sienaert P, Vansteelandt K, Demyttenaere K, Peuskens J. Ultra-brief pulse ECT in bipolar and unipolar depressive disorder: differences in speed of response. Bipolar Disord. 2009; 11(4):418 424. [PubMed: 19500095]

90. Fink M. How does convulsive therapy work? Neuropsychopharmacology. 1990; 3(2):73-82. [PubMed: 1969271]

91. Black DW, Winokur G, Nasrallah A. ECT in unipolar and bipolar disorders: a naturalistic evaluation of 460 patients. Convuls. Ther. 1986; 2(4):231-237. [PubMed: 11940870]

92. McCabe MS. ECT in the treatment of mania: a controlled study. Am. J. Psychiatry. 1976; 133(6): 688-691. [PubMed: 1275099]

93. Thomas J, Reddy B. The treatment of mania. A retrospective evaluation of the effects of ECT, chlorpromazine, and lithium. J. Affect. Disord. 1982; 4(2):85-92. [PubMed: 6213694]

94. Volpe FM, Tavares A. Manic patients receiving ECT in a Brazilian sample. J. Affect. Disord. 2004; 79(1-3):201-208. [PubMed: 15023495]

95. Medda P, Perugi G, Zanello S, Ciuffa M, Cassano GB. Response to ECT in bipolar I, bipolar II and unipolar depression. J. Affect. Disord. 2009; 118(1-3):55-59. [PubMed: 19223079]

96. Abrams R, Fink M. The present status of unilateral ECT. Some recommendations. J. Affect. Disord. 1984; 7(3-4):245-247. [PubMed: 6241207]

97. Small JG, Small IF, Milstein V, Kellams JJ, Klapper MH. Manic symptoms: an indication for bilateral ECT. Biol. Psychiatry. 1985; 20(2):125-134. [PubMed: 3970993]

98. Milstein V, Small JG, Klapper MH, Small IF, Miller MJ, Kellams JJ. Uni-versus bilateral ECT in the treatment of mania. Convuls. Ther. 1987; 3(1):1-9. [PubMed: 11940883]

99. Mukherjee S, Sackeim HA, Lee C. Unilateral ECT in the treatment of manic episodes. Convuls. Ther. 1988; 4(1):74-80. [PubMed: 11940944]

100. Devanand DP, Polanco P, Cruz R, et al. The efficacy of ECT in mixed affective states. J. ECT. 2000; 16(1):32-37. [PubMed: 10735329]

101. Koukopoulos A, Sani G, Koukopoulos AE, et al. Duration and stability of the rapid-cycling course: a long-term personal follow-up of 109 patients. J. Affect. Disord. 2003; 73(1-2):75-85. [PubMed: 12507740]

102. Zavorotnyy M, Diemer J, Patzelt J, Behnken A, Zwanzger P. Occurence of ultra-rapid cycling during electroconvulsive therapy in bipolar depression. World J. Biol. Psychiatry. 2009; 10(4 Pt 3):987-990. [PubMed: 19172530]

103. Dolenc TJ, Rasmussen KG. The safety of electroconvulsive therapy and lithium in combination: a case series and review of the literature. J. ECT. 2005; 21(3):165-170. [PubMed: 16127306]

104. Volpe FM, Tavares AR. Lithium plus ECT for mania in 90 cases: safety issues. J. Neuropsychiatry Clin. Neurosci. 2012; 24(4):E33. [PubMed: 23224476]

105. Mukherjee S, Sackeim HA, Schnur DB. Electroconvulsive therapy of acute manic episodes: a review of 50 years' experience. Am. J. Psychiatry. 1994; 151(2):169-176. [PubMed: 8296883]

106. Jobe TH, Harrow M. Long-term outcome of patients with schizophrenia: a review. Can. J. Psychiatry. 2005; 50(14):892-900. [PubMed: 16494258]

107. Lehnhardt FG, Konkol C, Kuhn J. Use of ECT in drug-refractory schizophrenia - a survey of the current literature. Fortschr. Neurol. Psychiatr. 2012; 80(9):501-511. [PubMed: 22706802]

108. Mouchet-Mages S. Electroconvulsive therapy and schizophrenia. Encephale. 2007; 33(Pt 3):S415-S418. [PubMed: 19101362]

109. Kales HC, Dequardo JR, Tandon R. Combined electroconvulsive therapy and clozapine in treatment-resistant schizophrenia. Prog. Neuropsychopharmacol. Biol. Psychiatry. 1999; 23(3): 547-556. [PubMed: 10378236] 
110. Gazdag G, Kocsis-Ficzere N, Tolna J. The augmentation of clozapine treatment with electroconvulsive therapy. Ideggyogy. Sz. 2006; 59(7-8):261-267. [PubMed: 17076304]

111. Kho KH, Blansjaar BA, de Vries S, Babuskova D, Zwinderman AH, Linszen DH. Electroconvulsive therapy for the treatment of clozapine nonresponders suffering from schizophrenia - an open label study. Eur. Arch. Psychiatry Clin. Neurosci. 2004; 254(6):372379. [PubMed: 15538604]

112. Philbrick KL, Rummans TA. Malignant catatonia. J. Neuropsychiatry Clin. Neurosci. 1994; 6(1): 1-13. [PubMed: 7908547]

113. Swartz C, Galang RL. Adverse outcome with delay in identification of catatonia in elderly patients. Am. J. Geriatr. Psychiatry. 2001; 9(1):78-80. [PubMed: 11156756]

114. Jaimes-Albornoz W, Serra-Mestres J. Catatonia in the emergency department. Emerg. Med. J. 2012; 29(11):863-867. [PubMed: 22389352]

115. Valenstein M, Maltbie A, Kaplan P. Catatonia in the emergency department. Ann. Emerg. Med. 1985; 14(4):359-361. [PubMed: 3985450]

116. Detweiler MB, Mehra A, Rowell T, Kim KY, Bader G. Delirious mania and malignant catatonia: a report of 3 cases and review. Psychiatr. Q. 2009; 80(1):23-40. [PubMed: 19199033]

117. Zervas IM, Theleritis C, Soldatos CR. Using ECT in schizophrenia: a review from a clinical perspective. World J. Biol. Psychiatry. 2012; 13(2):96-105. [PubMed: 21486108]

118. Suzuki K, Awata S, Matsuoka H. Short-term effect of ECT in middle-aged and elderly patients with intractable catatonic schizophrenia. J. ECT. 2003; 19(2):73-80. [PubMed: 12792454]

119. Suzuki K, Awata S, Takano T, et al. Adjusting the frequency of continuation and maintenance electroconvulsive therapy to prevent relapse of catatonic schizophrenia in middle-aged and elderly patients who are relapse-prone. Psychiatry Clin. Neurosci. 2006; 60(4):486-492. [PubMed: 16884452]

120. Starkstein SE, Petracca G, Tesón A, et al. Catatonia in depression: prevalence, clinical correlates, validation of a scale. J. Neurol. Neurosurg. Psychiatry. 1996; 60(3):326-332. [PubMed: 8609512]

121. Swartz CM, Morrow V, Surles L, James JF. Long-term outcome after ECT for catatonic depression. J. ECT. 2001; 17(3):180-183. [PubMed: 11528308]

122. Taylor MA, Abrams R. Catatonia. Prevalence and importance in the manic phase of manicdepressive illness. Arch. Gen. Psychiatry. 1977; 34(10):1223-1225. [PubMed: 911221]

123. Fink M. Delirious mania. Bipolar Disord. 1999; 1(1):54-60. [PubMed: 11256658]

124. White DA, Robins AH. Catatonia: harbinger of the neuroleptic malignant syndrome. Br. J. Psychiatry. 1991; 158:419-421. [PubMed: 1674666]

125. White DA. Catatonia and the neuroleptic malignant syndrome - a single entity? Br. J. Psychiatry. 1992; 161:558-560. [PubMed: 1393347]

126. White DA, Robins AH. An analysis of 17 catatonic patients diagnosed with neuroleptic malignant syndrome. CNS Spectr. 2000; 5(7):58-65. [PubMed: 18197157]

127. Luchini F, Lattanzi L, Bartolommei N, et al. Catatonia and neuroleptic malignant syndrome: two disorders on a same spectrum? Four case reports. J. Nerv. Ment. Dis. 2013; 201(1):36-42. [PubMed: 23274293]

128. Trollor JN, Sachdev PS. Electroconvulsive treatment of neuroleptic malignant syndrome: a review and report of cases. Aust. N. Z. J. Psychiatry. 1999; 33(5):650-659. [PubMed: 10544988]

129. Luchini F, Lattanzi L, Bartolommei N, et al. Catatonia and neuroleptic malignant syndrome: two disorders on a same spectrum? Three case reports. Riv. Psichiatr. 2012; 47(2):178-185. [PubMed: 22622253]

130. Casamassima F, Lattanzi L, Perlis RH, et al. Neuroleptic malignant syndrome: further lessons from a case report. Psychosomatics. 2010; 51(4):349-354. [PubMed: 20587766]

131. Askenazy F, Dor E, Benoit M, et al. Catatonia in a 14 year-old girl: treatment with clorazepam and carbamazepine, a 10-year follow-up. Encephale. 2010; 36(1):46-53. [PubMed: 20159196]

132. Berardi D, Amore M, Keck PE Jr, Troia M, Dell'Atti M. Clinical and pharmacologic risk factors for neuroleptic malignant syndrome: a case-control study. Biol. Psychiatry. 1998; 44(8):748754. [PubMed: 9798079] 
133. Cottencin O, Warembourg F, de Chouly de Lenclave MB, et al. Catatonia and consultationliaison psychiatry study of 12 cases. Prog. Neuropsychopharmacol. Biol. Psychiatry. 2007; 31(6): 1170-1176. [PubMed: 17537561]

134. Aloysi AS, Popeo DM, Kellner CH. Cases of catatonia on an academic electroconvulsive therapy service: lessons to learn. J. ECT. 2011; 27(3):259-261. [PubMed: 21206370]

135. Bush G, Fink M, Petrides G, Dowling F, Francis A. Catatonia. II. Treatment with lorazepam and electroconvulsive therapy. Acta Psychiatr. Scand. 1996; 93(2):137-143. [PubMed: 8686484]

136. Morena G, Sunderland B, Billig N. Midazolam and the treatment of catatonia in major depression in an older adult. Psychosomatics. 1994; 35(4):392-395. [PubMed: 8084989]

137. Carpenter SS, Hatchett AD, Fuller MA. Catatonic schizophrenia and the use of memantine. Ann. Pharmacother. 2006; 40(2):344-346. [PubMed: 16380435]

138. Obregon DF, Velasco RM, Wuerz TP, Catalano MC, Catalano G, Kahn D. Memantine and catatonia: a case report and literature review. J. Psychiatr. Pract. 2011; 17(4):292-299. [PubMed: 21775832]

139. McDaniel WW, Spiegel DR, Sahota AK. Topiramate effect in catatonia: a case series. J. Neuropsychiatry Clin. Neurosci. 2006; 18(2):234-238. [PubMed: 16720802]

140. Hervey WM, Stewart JT, Catalano G. Treatment of catatonia with amantadine. Clin. Neuropharmacol. 2012; 35(2):86-87. [PubMed: 22356926]

141. Raveendranathan D, Narayanaswamy JC, Reddi SV. Response rate of catatonia to electroconvulsive therapy and its clinical correlates. Eur. Arch. Psychiatry Clin. Neurosci. 2012; 262(5):425-430. [PubMed: 22207031]

142. Koek RJ, Mervis JR. Treatment-refractory catatonia, ECT, and parenteral lorazepam. Am. J. Psychiatry. 1999; 156(1):160-161. author reply 161. [PubMed: 9892323]

143. Factor SA, Molho ES, Podskalny GD, Brown D. Parkinson's disease: drug-induced psychiatric states. Adv. Neurol. 1995; 65:115-138. [PubMed: 7872135]

144. Holcomb HH, Sternberg DE, Heninger GR. Effects of electroconvulsive therapy on mood, parkinsonism, and tardive dyskinesia in a depressed patient: ECT and dopamine systems. Biol. Psychiatry. 1983; 18(8):865-873. [PubMed: 6615944]

145. Avorn J, Bohn RL, Mogun H, et al. Neuroleptic drug exposure and treatment of parkinsonism in the elderly: a case-control study. Am. J. Med. 1995; 99(1):48-54. [PubMed: 7598142]

146. Thanvi B, Treadwell S. Drug induced parkinsonism: a common cause of parkinsonism in older people. Postgrad. Med. J. 2009; 85(1004):322-326. [PubMed: 19528308]

147. Kalish SC, Bohn RL, Mogun H, Glynn RJ, Gurwitz JH, Avorn J. Antipsychotic prescribing patterns and the treatment of extrapyramidal symptoms in older people. J. Am. Geriatr. Soc. 1995; 43(9):967-973. [PubMed: 7657936]

148. Baez MA, Avery J. Improvement in drug-induced parkinsonism with electroconvulsive therapy. Am. J. Geriatr. Pharmacother. 2011; 9(3):190-193. [PubMed: 21565562]

149. Sadananda SK, Holla B, Viswanath B, et al. Effectiveness of electroconvulsive therapy for druginduced parkinsonism in the elderly. J. ECT. 2013; 29(1):e6-e7. [PubMed: 23422531]

150. Hermesh H, Aizenberg D, Friedberg G, Lapidot M, Munitz H. Electroconvulsive therapy for persistent neuroleptic-induced akathisia and parkinsonism: a case report. Biol. Psychiatry. 1992; 31(4):407-411. [PubMed: 1348431]

151. Hanin B, Lerner Y, Srour N. An unusual effect of ECT on drug-induced parkinsonism and tardive dystonia. Convuls. Ther. 1995; 11(4):271-274. [PubMed: 8919580]

152. Andersen K, Balldin J, Gottfries CG, et al. A double-blind evaluation of electroconvulsive therapy in Parkinson's disease with 'on-off' phenomena. Acta Neurol. Scand. 1987; 76(3):191199. [PubMed: 2446463]

153. Balldin J, Granérus AK, Lindstedt G, Modigh K, Wålinder J. Neuroendocrine evidence for increased responsiveness of dopamine receptors in humans following electroconvulsive therapy. Psychopharmacol. (Berl.). 1982; 76(4):371-376.

154. Levy LA, Savit JM, Hodes M. Parkinsonism: improvement by electroconvulsive therapy. Arch. Phys. Med. Rehabil. 1983; 64(9):432-433. [PubMed: 6615182] 
155. Bui E, Delrieu J, Wagner T, et al. Iodine-123 fluoropropyl-carbomethoxy-3-beta-(4iodophenyltropane) single-photon emission computed tomography findings before and after electroconvulsive therapy in major depressive disorder with parkinsonism. J. ECT. 2011; 27(4): 331-333. [PubMed: 21709584]

156. Pintor LP, Valldeoriola F, Fernández-Egea E, et al. Use of electroconvulsive therapy in Parkinson disease with residual axial symptoms partially unresponsive to 1-dopa: a pilot study. J. ECT. 2012; 28(2):87-91. [PubMed: 22531200]

157. Fall PA, Granerus AK. Maintenance ECT in Parkinson's disease. J. Neural Transm. 1999; 106(78):737-741. [PubMed: 10907732]

158. Nymeyer L, Grossberg GT. Delirium in a 75-year-old woman receiving ECT and levodopa. Convuls. Ther. 1997; 13(2):114-116. [PubMed: 9253532]

159. Zupancic M, Mahajan A, Handa K. Dementia with lewy bodies: diagnosis and management for primary care providers. Prim. Care Companion CNS Disord. 2011; 13(5) pii:PCC.11r01190.

160. Fratiglioni L, Launer LJ, Andersen K, et al. Incidence of dementia and major subtypes in Europe: a collaborative study of populationbased cohorts. Neurologic Diseases in the Elderly Research Group. Neurology. 2000; 54 Suppl. 5(11):S10-S15. [PubMed: 10854355]

161. Wragg RE, Jeste DV. Overview of depression and psychosis in Alzheimer's disease. Am. J. Psychiatry. 1989; 146(5):577-587. [PubMed: 2653053]

162. Bassiony MM, Steinberg MS, Warren A, Rosenblatt A, Baker AS, Lyketsos CG. Delusions and hallucinations in Alzheimer's disease: prevalence and clinical correlates. Int. J. Geriatr. Psychiatry. 2000; 15(2):99-107. [PubMed: 10679840]

163. Ropacki SA, Jeste DV. Epidemiology of and risk factors for psychosis of Alzheimer's disease: a review of 55 studies published from 1990 to 2003. Am. J. Psychiatry. 2005; 162(11):2022-2030. [PubMed: 16263838]

164. Burns A, Jacoby R, Levy R. Psychiatric phenomena in Alzheimer's disease. III: disorders of mood. Br. J. Psychiatry. 1990; 157:81-86. 92-94. [PubMed: 2397367]

165. Alexopoulos GS, Abrams RC. Depression in Alzheimer's disease. Psychiatr. Clin. North. Am. 1991; 14(2):327-340. [PubMed: 2062724]

166. Lyketsos CG, Steele C, Baker L, et al. Major and minor depression in Alzheimer's disease: prevalence and impact. J. Neuropsychiatry Clin. Neurosci. 1997; 9(4):556-561. [PubMed: 9447496]

167. Olfson M, Marcus S, Sackeim HA, Thompson J, Pincus HA. Use of ECT for the inpatient treatment of recurrent major depression. Am. J. Psychiatry. 1998; 155(1):22-29. [PubMed: 9433334]

168. Price TR, McAllister TW. Safety and efficacy of ECT in depressed patients with dementia: a review of clinical experience. Convuls. Ther. 1989; 5(1):61-74. [PubMed: 11940996]

169. Hausner L, Damian M, Sartorius A, Frölich L. Efficacy and cognitive side effects of electroconvulsive therapy (ECT) in depressed elderly inpatients with coexisting mild cognitive impairment or dementia. J. Clin. Psychiatry. 2011; 72(1):91-97. [PubMed: 21208587]

170. Oudman E. Is electroconvulsive therapy (ECT) effective and safe for treatment of depression in dementia? A short review. J. ECT. 2012; 28(1):34-38. [PubMed: 22330702]

171. Cohen-Mansfield J. Agitated behaviors in the elderly. II. Preliminary results in the cognitively deteriorated. J. Am. Geriatr. Soc. 1986; 34(10):722-727. [PubMed: 3760436]

172. Schneider LS, Pollock VE, Lyness SA. A metaanalysis of controlled trials of neuroleptic treatment in dementia. J. Am. Geriatr. Soc. 1990; 38(5):553-563. [PubMed: 1970586]

173. Tariot PN. Treatment of agitation in dementia. J. Clin. Psychiatry. 1999; 60(Suppl. 8):11-20. [PubMed: 10335667]

174. Deutsch LH, Bylsma FW, Rovner BW, Steele C, Folstein MF. Psychosis and physical aggression in probable Alzheimer's disease. Am. J. Psychiatry. 1991; 148(9):1159-1163. [PubMed: 1882992]

175. Deutsch LH, Bylsma FW, Rovner BW, Steele C, Folstein MF. Effectiveness of atypical antipsychotic drugs in patients with Alzheimer's disease. N. Engl. J. Med. 2006; 355(15):15251538. [PubMed: 17035647] 
176. Grant JE, Mohan SN. Treatment of agitation and aggression in four demented patients using ECT. J. ECT. 2001; 17(3):205-209. [PubMed: 11528314]

177. Ujkaj M, Davidoff DA, Seiner SJ, Ellison JM, Harper DG, Forester BP. Safety and efficacy of electroconvulsive therapy for the treatment of agitation and aggression in patients with dementia. Am. J. Geriatr. Psychiatry. 2012; 20(1):61-72. [PubMed: 22143072]

178. Miller ME, Siris SG, Gabriel AN. Treatment delays in the course of electroconvulsive therapy. Hosp. Community Psychiatry. 1986; 37(8):825-827. [PubMed: 3733014]

179. Linden T, Blomstrand C, Skoog I. Depressive disorders after 20 months in elderly stroke patients: a case-control study. Stroke. 2007; 38(6):1860-1863. [PubMed: 17431211]

180. Ghoge H, Sharma S, Sonawalla S, Parikh R. Cerebrovascular diseases and depression. Curr. Psychiatry Rep. 2003; 5(3):231-238. [PubMed: 12773278]

181. Carota A, Bogousslavsky J. Mood disorders after stroke. Front. Neurol. Neurosci. 2012; 30:7074. [PubMed: 22377867]

182. Hackett ML, Yang M, Anderson CS, Horrocks JA, House A. Pharmaceutical interventions for emotionalism after stroke. Cochrane Database Syst. Rev. 2010; 2:CD003690. [PubMed: 20166068]

183. Currier MB, Murray GB, Welch CC. Electroconvulsive therapy for post-stroke depressed geriatric patients. J. Neuropsychiatry Clin. Neurosci. 1992; 4(2):140-144. [PubMed: 1627974]

184. Prudic J, Peyser S, Sackeim HA. Subjective memory complaints: a review of patient selfassessment of memory after electroconvulsive therapy. J. ECT. 2000; 16(2):121-132. [PubMed: 10868322]

185. Prudic J, Olfson M, Marcus SC, Fuller RB, Sackeim HA. Effectiveness of electroconvulsive therapy in community settings. Biol. Psychiatry. 2004; 55(3):301-312. [PubMed: 14744473]

186. Berman RM, Prudic J, Brakemeier EL, Olfson M, Sackeim HA. Subjective evaluation of the therapeutic and cognitive effects of electroconvulsive therapy. Brain Stimul. 2008; 1(1):16-26. [PubMed: 20633366]

187. Coffey, CE.; Weiner, RD. American Psychiatric Association. The Practice of Electroconvulsive Therapy Recommendations for Treatment, Training, and Privileging. 2nd Edition. Washington, DC: American Psychiatric Association; 2001. p. 355

188. Sackeim HA, Prudic J, Nobler MS, et al. Effects of pulse width and electrode placement on the efficacy and cognitive effects of electroconvulsive therapy. Brain Stimul. 2008; 1(2):71-83. [PubMed: 19756236] . - The use of an ultrabrief stimulus markedly reduces adverse cognitive effects, and when coupled with markedly suprathreshold right unilateral ECT, also preserves efficacy.

189. Loo C, Sheehan P, Pigot M, Lyndon W. A report on mood and cognitive outcomes with right unilateral ultrabrief pulsewidth $(0.3 \mathrm{~ms})$ ECT and retrospective comparison with standard pulsewidth right unilateral ECT. J. Affect. Disord. 2007; 103(1-3):277-281. [PubMed: 17706790]

190. Peterchev AV, Rosa MA, Deng ZD, Prudic J, Lisanby SH. Electroconvulsive therapy stimulus parameters: rethinking dosage. J. ECT. 2010; 26(3):159-174. [PubMed: 20805726]

191. Loo CK, Katalinic N, Martin D, Schweitzer I. A review of ultrabrief pulse width electroconvulsive therapy. Ther. Adv. Chronic Dis. 2012; 3(2):69-85. [PubMed: 23251770]

192. Dunne RA, McLoughlin DM. Systematic review and meta-analysis of bifrontal electroconvulsive therapy versus bilateral and unilateral electroconvulsive therapy in depression. World J. Biol. Psychiatry. 2012; 13(4):248-258. [PubMed: 22098115]

193. Coffey CE, Lucke J, Weiner RD, Krystal AD, Aque M. Seizure threshold in electroconvulsive therapy (ECT) II. The anticonvulsant effect of ECT. Biol. Psychiatry. 1995; 37(11):777-788. [PubMed: 7647162]

194. McCall WV, Weiner RD, Carroll BJ, et al. Serum prolactin, electrode placement, and the convulsive threshold during ECT. Convuls. Ther. 1996; 12(2):81-85. [PubMed: 8744166]

195. Sackeim HA, Devanand DP, Prudic J. Stimulus intensity, seizure threshold, and seizure duration: impact on the efficacy and safety of electroconvulsive therapy. Psychiatr. Clin. North. Am. 1991; 14(4):803-843. [PubMed: 1771150] 
196. Coffey CE, Weiner RD. ECT instrumentation. Biol. Psychiatry. 1988; 24(3):361-363. [PubMed: 3401529]

197. Cronholm B, Ottosson JO. Ultrabrief stimulus technique in electroconvulsive therapy. II. Comparative studies of therapeutic effects and memory disturbances in treatment of endogenous depression with the elther es electroshock apparatus and siemens konvulsator III. J. Nerv. Ment. Dis. 1963; 137:268-276. [PubMed: 14051942]

198. Sobin C, Sackeim HA, Prudic J, Devanand DP, Moody BJ, McElhiney MC. Predictors of retrograde amnesia following ECT. Am. J. Psychiatry. 1995; 152(7):995-1001. [PubMed: 7793470]

199. Reid WH, Keller S, Leatherman M, Mason M. ECT in Texas: 19 months of mandatory reporting. J. Clin. Psychiatry. 1998; 59(1):8-13. [PubMed: 9491059]

200. Watts BV, Groft A, Bagian JP, Mills PD. An examination of mortality and other adverse events related to electroconvulsive therapy using a national adverse event report system. J. ECT. 2011; 27(2):105-108. [PubMed: 20966769]

201. Nuttall GA, Bowersox MR, Douglass SB, et al. Morbidity and mortality in the use of electroconvulsive therapy. J. ECT. 2004; 20(4):237-241. [PubMed: 15591857]

202. Rasmussen KG, Jarvis MR, Zorumski CF, et al. Low-dose atropine in electroconvulsive therapy. J. ECT. 1999; 15(3):213-221. [PubMed: 10492860]

203. Prudic J, Sackeim HA, Decina P, et al. Acute effects of ECT on cardiovascular functioning: relations to patient and treatment variables. Acta Psychiatr. Scand. 1987; 75(4):344-351. [PubMed: 3591419]

204. Swartz CM, Saheba NC. Comparison of atropine with glycopyrrolate for use in ECT. Convuls. Ther. 1989; 5(1):56-60. [PubMed: 11940995]

205. Lloyd-Jones DM, Evans JC, Levy D. Hypertension in adults across the age spectrum: current outcomes and control in the community. JAMA. 2005; 294(4):466-472. [PubMed: 16046653]

206. Webb MC, Coffey CE, Saunders WR, Cress MM, Weiner RD, Sibert TR. Cardiovascular response to unilateral electroconvulsive therapy. Biol. Psychiatry. 1990; 28(9):758-766. [PubMed: 2257285]

207. Tess AV, Smetana GW. Medical evaluation of patients undergoing electroconvulsive therapy. N. Engl. J. Med. 2009; 360(14):1437-1444. [PubMed: 19339723]

208. Shrestha S, Shrestha BR, Thapa C, Pradhan SN, Thapa R, Adhikari S. Comparative study of esmolol and labetalol to attenuate haemodynamic responses after electroconvulsive therapy. Kathmandu Univ. Med. J. (KUMJ). 2007; 5(3):318-323. [PubMed: 18604047]

209. van den Broek WW, Leentjens AF, Mulder PG, Kusuma A, Bruijn JA. Low-dose esmolol bolus reduces seizure duration during electroconvulsive therapy: a double-blind, placebo-controlled study. Br. J. Anaesth. 1999; 83(2):271-274. [PubMed: 10618942]

210. Albin SM, Stevens SR, Rasmussen KG. Blood pressure before and after electroconvulsive therapy in hypertensive and nonhypertensive patients. J. ECT. 2007; 23(1):9-10. [PubMed: 17435564]

211. Zielinski RJ, Roose SP, Devanand DP, Woodring S, Sackeim HA. Cardiovascular complications of ECT in depressed patients with cardiac disease. Am. J. Psychiatry. 1993; 150(6):904-909. [PubMed: 8494067]

212. Stern L, Hirschmann S, Grunhaus L. ECT in patients with major depressive disorder and low cardiac output. Convuls. Ther. 1997; 13(2):68-73. [PubMed: 9253526]

213. Rivera FA, Lapid MI, Sampson S, Mueller PS. Safety of electroconvulsive therapy in patients with a history of heart failure and decreased left ventricular systolic heart function. J. ECT. 2011; 27(3):207-213. [PubMed: 21865957]

214. Devanand DP, Malitz S, Sackeim HA. ECT in a patient with aortic aneurysm. J. Clin. Psychiatry. 1990; 51(6):255-256. [PubMed: 2347864]

215. Mueller PS, Barnes RD, Varghese R, Nishimura RA, Rasmussen KG. The safety of electroconvulsive therapy in patients with severe aortic stenosis. Mayo Clin. Proc. 2007; 82(11): 1360-1363. [PubMed: 17976355] 
216. Mueller PS, Albin SM, Barnes RD, Rasmussen KG Jr. Safety of electroconvulsive therapy in patients with unrepaired abdominal aortic aneurysm: report of 8 patients. J. ECT. 2009; 25(3): 165-169. [PubMed: 19730028]

217. Serby MJ, Lantz M, Chabus BI, Bernay LJ. Takotsubo cardiomyopathy and electroconvulsive treatments: a case study and review. Int. J. Psychiatry Med. 2010; 40(1):93-96. [PubMed: 20565047]

218. Celano CM, Torri A, Seiner S. Takotsubo cardiomyopathy after electroconvulsive therapy: a case report and review. J. ECT. 2011; 27(3):221-223. [PubMed: 21673587]

219. Satterthwaite TD, Cristancho MA, Alici Y, Weiss D, O'Reardon JP. Electroconvulsive therapy in a 72-year-old woman with a history of Takotsubo cardiomyopathy: a case report and review of the literature. Brain Stimul. 2009; 2(4):238-240. [PubMed: 20633423]

220. Kent LK, Weston CA, Heyer EJ, Sherman W, Prudic J. Successful retrial of ECT two months after ECT-induced takotsubo cardiomyopathy. Am. J. Psychiatry. 2009; 166(8):857-862. [PubMed: 19651751]

221. Beach SR, Wichman CL, Canterbury RJ. Takotsubo cardiomyopathy following electroconvulsive therapy. J. Cardiovasc. Med. (Hagerstown). 2009; 10(4):333-335. [PubMed: 19430344]

222. O'Reardon JP, Lott JP, Akhtar UW, Cristancho P, Weiss D, Jones N. Acute coronary syndrome (Takotsubo cardiomyopathy) following electroconvulsive therapy in the absence of significant coronary artery disease: case report and review of the literature. J. ECT. 2008; 24(4):277-280. [PubMed: 18955900]

223. Devanand DP, Decina P, Sackeim HA, Prudic J. Status epilepticus following ECT in a patient receiving theophylline. J. Clin. Psychopharmacol. 1988; 8(2):153. [PubMed: 3372714]

224. Williams J, Rosenquist P, Arias L, McCall WV. Pseudocholinesterase deficiency and electroconvulsive therapy. J. ECT. 2007; 23(3):198-200. [PubMed: 17805000]

225. Mueller PS, Schak KM, Barnes RD, Rasmussen KG. Safety of electroconvulsive therapy in patients with asthma. Neth. J. Med. 2006; 64(11):417-421. [PubMed: 17179572]

226. Figiel GS, Jarvis MR. Electroconvulsive therapy in a depressed patient receiving bupropion. J. Clin. Psychopharmacol. 1990; 10:376. [PubMed: 2124220]

227. Sadananda SK, Narayanaswamy JC, Srinivasaraju R, Math SB. Delirium during the course of electroconvulsive therapy in a patient on lithium carbonate treatment. Gen. Hosp. Psychiatry. 2013; 35(6):678, e1-e2. [PubMed: 23517818]

228. Rudorfer MV, Manji HK, Potter WZ. ECT and delirium in Parkinson's disease. Am. J. Psychiatry. 1992; 149(12):1758-1759. author reply 1759-1760. [PubMed: 1443266]

229. Kikuchi A, Yasui-Furukori N, Fujii A, Katagai H, Kaneko S. Identification of predictors of postictal delirium after electroconvulsive therapy. Psychiatry Clin. Neurosci. 2009; 63(2):180-185. [PubMed: 19335388]

230. Figiel GS, Hassen MA, Zorumski C, et al. ECT-induced delirium in depressed patients with Parkinson's disease. J. Neuropsychiatry Clin. Neurosci. 1991; 3(4):405-411. [PubMed: 1821261]

231. Rao V, Lyketsos CG. The benefits and risks of ECT for patients with primary dementia who also suffer from depression. Int. J. Geriatr. Psychiatry. 2000; 15(8):729-735. [PubMed: 10960885]

232. Kelly KG, Zisselman M. Update on electroconvulsive therapy (ECT) in older adults. J. Am. Geriatr. Soc. 2000; 48(5):560-566. [PubMed: 10811552]

233. Figiel GS, Coffey CE, Djang WT, Hoffman G Jr, Doraiswamy PM. Brain magnetic resonance imaging findings in ECT-induced delirium. J. Neuropsychiatry Clin. Neurosci. 1990; 2(1):53-58. [PubMed: 2136061]

234. Figiel GS, Krishnan KR, Doraiswamy PM. Subcortical structural changes in ECT-induced delirium. J. Geriatr. Psychiatry Neurol. 1990; 3(3):172-176. [PubMed: 2282134]

235. Martin M, Figiel G, Mattingly G, Zorumski CF, Jarvis MR. ECT-induced interictal delirium in patients with a history of a CVA. J. Geriatr. Psychiatry Neurol. 1992; 5(3):149-155. [PubMed: 1497792]

236. Logan CJ, Stewart JT. Treatment of post-electroconvulsive therapy delirium and agitation with donepezil. J. ECT. 2007; 23(1):28-29. [PubMed: 17435571]

237. Swartz CM. Electroconvulsive therapy emergence agitation and succinylcholine dose. J. Nerv. Ment. Dis. 1990; 178(7):455-457. [PubMed: 2366059] 
238. Andersen KL, Videbech P. Treatment of postictal (emergence) delirium after electroconvulsive therapy. Ugeskr. Laeger. 2005; 167(35):3313-3314. [PubMed: 16138979]

239. Fraser LM, O'Carroll RE, Ebmeier KP. The effect of electroconvulsive therapy on autobiographical memory: a systematic review. J. ECT. 2008; 24(1):10-17. [PubMed: 18379329]

240. Devanand DP, Verma AK, Tirumalasetti F, Sackeim HA. Absence of cognitive impairment after more than 100 lifetime ECT treatments. Am. J. Psychiatry. 1991; 148(7):929-932. [PubMed: 2053635] . The results suggest that patients given many ECT treatments over several courses do not manifest measurable cognitive impairment at long-term follow-up.

241. Prudic J, Olfson M, Sackeim HA. Electro-convulsive therapy practices in the community. Psychol. Med. 2001; 31(5):929-934. [PubMed: 11459391]

242. Brodaty H, Hickie I, Mason C, Prenter L. A prospective follow-up study of ECT outcome in older depressed patients. J. Affect. Disord. 2000; 60(2):101-111. [PubMed: 10967369]

243. Brodaty H, Berle D, Hickie I, Mason C. 'Side effects' of ECT are mainly depressive phenomena and are independent of age. J. Affect. Disord. 2001; 66(2-3):237-245. [PubMed: 11578677]

244. Devanand DP, Sackeim HA, Prudic J. Electroconvulsive therapy in the treatment-resistant patient. Psychiatr. Clin. North. Am. 1991; 14(4):905-923. [PubMed: 1771153]

245. Kellner CH, Knapp RG, Petrides G, et al. Continuation electroconvulsive therapy vs pharmacotherapy for relapse prevention in major depression: a multisite study from the Consortium for Research in Electroconvulsive Therapy (CORE). Arch. Gen. Psychiatry. 2006; 63(12):1337-1344. [PubMed: 17146008]

246. O'Connor DW, Gardner B, Presnell I, Singh D, Tsanglis M, White E. The effectiveness of continuation-maintenance ECT in reducing depressed older patients' hospital re-admissions. J. Affect. Disord. 2010; 120(1-3):62-66. [PubMed: 19411112] . - Suggests that continuationmaintenance ECT is effective in carefully selected patients at high risk of relapse.

247. van Schaik AM, Comijs HC, Sonnenberg CM, Beekman AT, Sienaert P, Stek ML. Efficacy and safety of continuation and maintenance electroconvulsive therapy in depressed elderly patients: a systematic review. Am. J. Geriatr. Psychiatry. 2012; 20(1):5-17. [PubMed: 22183009] . - On the basis of available literature, maintenance-ECT is probably as effective as continuation medication in severely depressed elderly patients after a successful course of ECT and is generally well tolerated.

248. Chanpattana W, Chakrabhand ML, Sackeim HA, et al. Continuation ECT in treatment-resistant schizophrenia: a controlled study. J. ECT. 1999; 15(3):178-192. [PubMed: 10492856]

249. Kellner, CH. Brain Stimulation in Psychiatry. ECT, DBS, TMS and Other Modalities. Cambridge, UK: Cambridge University Press; 2012. Magnetic seizure therapy (MST); p. 127-130.

250. Rowny SB, Cycowicz YM, McClintock SM, Truesdale MD, Luber B, Lisanby SH. Differential heart rate response to magnetic seizure therapy (MST) relative to electroconvulsive therapy: a nonhuman primate model. Neuroimage. 2009; 47(3):1086-1091. [PubMed: 19497373]

251. Allan CL, Ebmeier KP. The use of ECT and MST in treating depression. Int. Rev. Psychiatry. 2011; 23(5):400-412. [PubMed: 22200130]

252. McClintock SM, Tirmizi O, Chansard M, Husain MM. A systematic review of the neurocognitive effects of magnetic seizure therapy. Int. Rev. Psychiatry. 2011; 23(5):413-423. [PubMed: 22200131]

\section{Websites}

301. ClinicalTrials.gov. Focal Electroconvulsive Therapy for Depression (FEAST). http:// clinicaltrials.gov/show/NCT01589315

302. ClinicalTrials.gov. Cognitive Training for Memory Deficits Associated With Electroconvulsive Therapy. http://clinicaltrials.gov/show/NCT01876758 


\section{Practice points}

Psychiatric disorders

- $\quad$ Electroconvulsive therapy (ECT) may be the most effective and rapid treatment available for elderly patients who have severe major depressive disorder, or bipolar mania or bipolar depression.

- $\quad$ Current ECT practice guidelines recommend ECT as an augmentation strategy in treatment-refractory schizophrenia.

Neuropsychiatric disorders

- $\quad$ Elderly patients with catatonia, including schizophrenia with intractable catatonia, delirious mania with catatonic features, neuroleptic malignant syndrome and catatonia secondary to critical medical conditions, can be treated effectively with acute ECT.

- $\quad$ ECT can be an effective treatment for psychosis induced by antiparkinsonian drugs.

- $\quad$ ECT can improve motor function in severe idiopathic Parkinson's disease with 'on-off' phenomena.

- $\quad$ ECT is a well-tolerated and effective treatment for poststroke depression and for dementia with potentially life-threatening behavioral disturbances, depression and psychosis.

Continuation ECT \& maintenance ECT

- $\quad$ Continuation ECT and maintenance ECT are effective in elderly patients.

- ECT adverse effects \& management

- $\quad$ Delirium and confusion are transient and reversible in most cases.

- $\quad$ ECT can be given with relative safety to elderly patients with severe cardiovascular disease, chronic obstructive pulmonary disease and active asthma, when treatment for cardiac or pulmonary conditions before ECT is optimized.

- Maximizing ECT efficacy \& minimizing ECT side effects

- $\quad$ Right unilateral ECT has fewer cognitive adverse effects than bilateral ECT while efficacy can be made equivalent to bilateral ECT with adequate dosing.

- $\quad$ Stimulus intensity for unilateral ECT should be 2.5- to 8-times of seizure threshold to yield the best ECT effectiveness. 


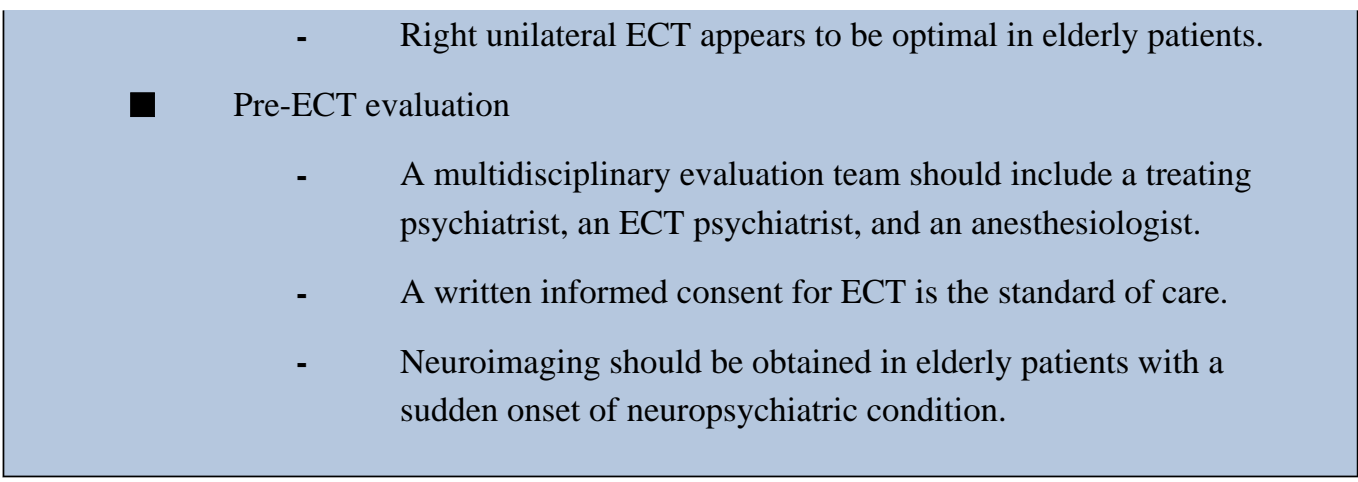


Table 1

Differences between brief pulse and ultrabrief pulse stimuus.

\begin{tabular}{|lllll|}
\hline Electrical waveform & History utilization & Seizure induction & Memory problems & $\begin{array}{l}\text { Pulse } \\
\text { width (ms) }\end{array}$ \\
\hline Brief pulse & 1970s-present & Efficient & Moderate & $0.5-2.0$ \\
\hline Ultrabrief pulse & 1990s-present & More efficient & Limited & $<0.5$ \\
\hline
\end{tabular}


Table 2

Differences among anesthetic agents and muscle relaxants.

\begin{tabular}{|c|c|c|c|}
\hline Drug & Dose (mg/kg) & Benefits & Side effects \\
\hline \multicolumn{4}{|l|}{ Anesthetic agents } \\
\hline Methohexital & $0.75-1.0$ & $\begin{array}{l}\text { Rapid action } \\
\text { Less post-ECT confusion }\end{array}$ & - \\
\hline Thiopental & $2.0-4.0$ & - & Increased risk of bradycardia \\
\hline Propofol & $1.0-1.5$ & $\begin{array}{l}\text { Less cardiotoxicity } \\
\text { Shorter half-life }\end{array}$ & Reduced duration of seizure \\
\hline Etomidate & $0.15-0.3$ & $\begin{array}{l}\text { Minimal cardiac side effects; } \\
\text { low anticonvulsant effects }\end{array}$ & Post-ECT confusion \\
\hline Ketamine & $1.5-2.0$ & - & $\begin{array}{l}\text { Cardiotoxicity } \\
\text { Transient psychosis }\end{array}$ \\
\hline \multicolumn{4}{|l|}{ Muscle relaxants } \\
\hline Succinylcholine & $0.5-1.25$ & $\begin{array}{l}\text { Rapid onset } \\
\text { Fast offset }\end{array}$ & Hyperkalemia \\
\hline Mivacurium & 0.2 & Alternative to succinylcholine & Longer acting; requires reversal \\
\hline
\end{tabular}

ECT: Electroconvulsive therapy. 
Table 3

Differences among electrode placements.

\begin{tabular}{|lllll|}
\hline $\begin{array}{l}\text { Electrode } \\
\text { placement }\end{array}$ & Positioning & $\begin{array}{l}\text { Seizure } \\
\text { threshold }\end{array}$ & Antidepressant efficacy & $\begin{array}{l}\text { Cognitive side } \\
\text { effects }\end{array}$ \\
\hline Bifrontal & $\begin{array}{l}\text { Superior to each } \\
\text { external canthus }\end{array}$ & High & $\begin{array}{l}\text { Equal to } \\
\text { bilateral }\end{array}$ & Possibly less than bilateral \\
\hline Bilateral & Bifrontotemporal & Higher & Standard & Significant \\
\hline R-unilateral & $\begin{array}{l}\text { R-frontotemporal } \\
\text { R-centroparietal }\end{array}$ & Lower & $\begin{array}{l}\text { Equally to bilateral with } \\
\text { adequate dosing }\end{array}$ & Minimum \\
\hline
\end{tabular}

R: Right. 